\title{
Renewable energy emulation concepts for microgrids
}

\author{
E. Prieto-Araujo ${ }^{\text {a }}$, P. Olivella-Rosell ${ }^{\mathrm{a}}$, M. Cheah-Mañe ${ }^{\mathrm{a}}$, R. Villafafila-Robles ${ }^{\mathrm{a}}$, \\ O. Gomis-Bellmunt ${ }^{\mathrm{a}}$ \\ ${ }^{a}$ Centre d'Innovació Tecnològica en Convertidors Estàtics i Accionaments (CITCEA-UPC), Departament \\ d'Enginyeria Elèctrica, Universitat Politècnica de Catalunya. ETS d'Enginyeria Industrial de Barcelona, Av. \\ Diagonal, 647, Pl. 2. 08028 Barcelona, Spain
}

\begin{abstract}
This article reviews the renewable energy systems emulators proposals for microgrid laboratory testing platforms. Four emulation conceptual levels are identified based on the literature analysis performed. Each of these levels is explained through a microgrid example, detailing its features and possibilities. Finally, an experimental microgrid, built based on emulators, is presented to exemplify the system performance.

Keywords: Emulators, Renewable energy, Platform laboratory, Power electronics.
\end{abstract}

\section{Introduction}

The importance of distributed generation (DG) in the power system is increasing. The energy produced in these facilities must be integrated to the grid and microgrids arise as a particularly beneficial solution. A microgrid is defined as a system compounded by different micro-sources and loads, operated by an energy manager, that is able to deliver heat and electrical power in a local area [1]. This definition has been evolving as other capabilities has been included to the concept as storage systems [2] or the islanding system operation [3]. Microgrids should be understood as small pieces of the whole power system and each of them could be designed and operated to meet different local specifications and objectives.

A microgrid is a relatively new concept, thus different studies related with the control, operation, design and protection are being developed. Among all these projects, the ones where real microgrids are built [4], are extremely interesting for testing the theoretical developments. Microgrids as the CERTS laboratory project (Consortium for Electrical Reliability Technology

Email address: eduardo.prieto-araujo@citcea.upc.edu (E. Prieto-Araujo) 
Solutions) [5] or facilities developed by other research centers are defining the specifications of the future microgrid concept [6]. In a laboratory scale, other setups are being built, as for example the IREC microgrid (Catalonia Institute for Energy Research) [7] or the platform proposed by the Energy Systems Research Laboratory, Florida International University [8]. These laboratory platforms, in contrast to the large experimental projects, include emulation devices which allow to physically represent the behavior of many different resources. Emulators in combination with real systems, increase the experimental laboratory platform capabilities enormously.

Focused on the emulation devices, this paper reviews the emulation structures proposed in the literature. As a result, emulation is divided in four different conceptual groups, defined as the emulation levels. To clarify this concept, the different emulation levels features and characteristics are explained through an example microgrid layout, also including a complete classification of the literature review. Finally, a real laboratory platform, employing two of the emulation levels defined, is presented. Three different emulators are included in this system, one acting as a photovoltaic panel, another as a battery and another one as a couple of loads, defining the basic structure of a microgrid. Experimental results are included to show the actual operation of the system including the emulators and its testing possibilities.

\section{The emulation concept}

An emulator is a device that attempts to mimic the behavior of a real resource. Basically, it is compounded by two interrelated parts, a software and a hardware layer. On the one hand, the software layer calculates the system variables, that the real system would show under the same conditions, based on static or dynamic operations. On the other hand, the hardware layer imposes the software calculated variables by means of mechanical, electronic or electrical devices, to follow the real system behavior. According to the previous definition, systems of all kinds could be emulated. However, this article is mainly focused on analyzing the emulation structures available for representing energy systems that could be connected to an electrical microgrid.

In order to clarify the introduced concept, an example of a photovoltaic (PV) emulator operation (Figure 1) connected to the grid is explained in detail. In this case, the emulator software layer calculates, based on the real PV installation that is being emulated and the environmental scenario conditions defined for the experiment, the voltage that would be across the real PV 
power connection terminals. Once calculated, this voltage is applied by the emulator hardware layer at the emulator power terminals, by means, for instance, of a power converter. Therefore, both the real PV installation and the emulator would show the same voltage at its connection terminals, allowing the grid integration converter to perform the same control on them, without any difference.

[Figure 1 about here.]

In general, emulation devices present some features that increase the possibilities of the testing system where they are connected, regardless of the resource that is being represented:

- An emulator can represent any possible scenario employing the same software and hardware devices. The experiment conditions are imposed by the user.

- Experiments performed employing emulators avoid damaging real setups. Emulators usually include protections and securities to avoid possible problems while testing.

- Emulation allow to change the experiments time scale. For instance, long time evolution of the real system can be concentrated in a short period of time.

- Emulators are usually smaller than the emulated real setups. This feature is interesting for laboratory test benches where the testing space is usually limited.

- Its hardware and associated costs are usually lower in comparison to real systems.

- In certain configurations, an emulator is able to represent different resources or an aggregation of various systems.

- The emulator output power could be scaled to a larger one if it is needed. The hardware can be designed for a desired power level and otherwise, the software layer can scale the results of the emulation.

As it is mentioned above, the inclusion of emulators in experimental microgrid research setups could be interesting to test different aspects [9] as the system control, the islanding operation mode, the grid integration of the resources by means of power electronics, the design and operation of 
microgrid energy management systems and the protection, operation and control of AC and DC electrical microgrids, among others.

\section{Emulation levels definition}

Based on the emulator literature review developed, it can be stated that emulators can be conceptually classified in different groups, defined in this work as the emulation levels. These levels are defined based on the degree of detail employed to represent the emulated resource, not on the software and hardware devices used for the emulation. In this section, the established emulation levels are explained using the example microgrid layout depicted in Figure 2.

[Figure 2 about here.]

The example microgrid scheme is divided in two different current nature grids, the AC side (black lines) where loads and conventional microgeneration are connected and the DC side (blue lines) where the renewable generation and storage systems are placed. The connection of the different resources to the DC microgrid part is carried out using $\mathrm{DC} / \mathrm{DC}$ or $\mathrm{AC} / \mathrm{DC}$ converters, depending on the system current nature. Note also that, the nature of the AC grid is not specified, thus it can be a single-phase, a three-phase or a multi-phase grid.

Once introduced the example layout, the emulation levels are explained, starting from the most generalized, to the most specific ones. Basically, the development of the different levels will be focused on the DC grid side elements of the example microgrid. It should be mentioned that converters drawn with dashed lines are related with emulation, whereas those drawn with solid lines are considered real elements.

\subsection{Level 1: Global emulation}

Figure 3 shows the most possible generic emulation of systems, defined as global emulation. This level considers that the generation, storage and load systems connected to a certain grid could be emulated via software (represented by a red square in Figure 3) and transformed into an equivalent aggregated active and reactive power consumed or injected to the microgrid by a single hardware layer. The emulator is not representing a single resource, it is representing the aggregation of a whole system with its different subsystems connected to it. 
[Figure 3 about here.]

Therefore, the emulation system exchanges a defined amount of the power with the grid based on the total power aggregation computed by the software layer. If it is desired, an individual control could be applied on each resource, but it has to be implemented in the software stage of the emulation. Experiments related with microgrid grid integration, communications, coordination and control between different microgrids could be performed.

Note that, the green block depicted in Figure 3, corresponds to the power supply (PS) of the emulators, needed for the system operation. Then, if the emulation system consumes energy from the DC grid, this energy must be consumed by the PS system and on the contrary, if the emulation is injecting power to the grid, the PS should deliver it. Therefore, the PS must be bidirectional to accomplish the emulation system requirements. However, if the nature of the emulated system is defined, the PS could be design to be unidirectional. Hereinafter, the PS system is depicted using a green box connected to the emulators.

\subsection{Level 2: Aggregated emulation of generation, storage and loads}

This architecture consists on gathering the emulated systems by common flow direction. As it is shown in Figure 4, three different branches can be differentiated. These branches correspond to three emulation groups, generation, storage and loads. The emulator software layer computes the aggregation of different resources by power flow nature, calculating the equivalent power that they are injecting or absorbing from the grid. Then, the hardware layer, transforms this calculation

in a real power flow. The difference between this emulation level and the previous one is purely conceptual, because the same emulation devices could perform both emulations perfectly. Again, an specific control applied to a single resource has to be computed in the software layer, because everything is calculated in it.

[Figure 4 about here.]

This architecture is useful for testing microgrid energy management systems, communications, among others. 


\subsection{Level 3: Resource emulation}

The conceptual diagram of this emulation is shown in Figure 5. Unlike the two previous emulation levels, this architecture dedicates an emulator device to each resource. The emulators

employed in this level are power emulators, thus they represent the power output that the real resource system would be exchanging with the grid, under the defined conditions. Then, not only the behavior of the resource is being emulated, but also the possible interconnection systems between the resource and the grid. For instance, a solar panel would be emulated together with the converter that is used for the grid integration of the energy produced. The software layer of the emulator calculates the variables of the system and the power output that the whole real system would be injecting under the same conditions, and the hardware layer will transform the software calculations into real power.

[Figure 5 about here.]

The difference between this emulation level and the previous ones is again conceptual, because the same emulator devices could be used for the three different levels. However, this architecture does not allow again to perform real control of the emulated resource because the system is based in power emulation, so if it is desired, it should be implemented in the software layer. This emulation concept allows to perform experiments, at a resource level, related with microgrid energy management systems, grid integration of the resources, communications between systems, coordination, protections, among others.

\subsubsection{Level 4: Specific emulation}

This emulation level (Figure 6) is focused on the emulation of a resource by representing its electrical variables. The software layer carries out the calculation of the resource variables under the defined scenario conditions and the hardware layer applies these variables to the real system. For instance, the operation of a PV panel could be emulated. Based on a supposed irradiance, the software layer calculates the voltage output that the real system would be applying. Then, the hardware layer regulates the voltage at the output terminals, to apply exactly the calculated magnitude. Therefore, if a grid integration converter is connected to the emulator, it will not detect any difference between the emulator and the real system if the first is properly designed. 
This fact can be observed in Figure 6 where real DC/DC converters are performing the integration of the emulators to the real grid, in the same way as it would be connecting the real resources to the microgrid.

[Figure 6 about here.]

There is an important difference between the emulation concept employed in this level and the previous ones. While in emulation level 3, the emulators act as power sources; in this case, emulators are representing mainly the resource, applying, for instance, the same voltage that the real resource would be applying under the same conditions. Therefore, this level allows to perform real control on the emulators, as if they were real resources. Moreover, this emulation level allows to swap the emulator by the real emulated resource.

This emulation level defines a boundary on the conceptualization of the emulators. More complex structures can be defined for each resource individually, but further conceptual groups are not easy to be made. Figure 7 shows further emulation possibilities focusing on each of the elements that compound the microgrid, starting from the emulation presented above in Figure 6 (indicated with a number 1), to the real system implementation where the emulator is substituted by a real installation. Next, these structures are described:

- Wind energy emulation

1. Turbine-generator emulator. The emulator is designed to represent the electrical system gathering the wind turbine and the generator.

2. Turbine emulation. The wind resource and the turbine are emulated by a motor controlled by a frequency converter. The motor axis is coupled to the real (or scaled) generator. Then, supposing a wind resource and defining the turbine blades, the torque or the speed of the motor could be calculated and regulated by the frequency converter. Then, the real generator could be controlled by a real converter.

3. Wind emulation. The generator and the turbine are the real ones (or a scaled version). The wind is emulated using a fan, allowing to perform real tests with the whole setup.

4. Real wind generation system. The wind emulation system is replaced by the real resource. 
- Solar energy emulation

1. PV cell emulator. The emulator represents the behavior of a PV cell or a combination of them.

2. Light emulation. The PV emulator is replaced by the real panel (or a scaled version) and it is excited by artificial light.

3. Real PV installation. The solar emulation system is replaced by the real resource.

- Battery emulation

1. Battery emulator. The emulator represents the behavior of a battery. It could be designed and configured to represent any type of battery.

2. Real batteries. The emulator is replaced by a real battery system.

- Electric vehicle emulation

1. Electric vehicle emulator. The electric vehicle behavior is represented by an emulator. It can be configured as a fast or conventional charging system. It also could include not only the electrical part, but also the communications including different protocols.

2. Real EV with fast charging capability. The EV emulator is substituted by a car with fast charging capability.

3. Real EV with conventional battery charger. The EV emulator is substituted by a car with a conventional charging capability.

- Flywheel emulation

1. Flywheel-generator emulator. The flywheel together with the generator behavior is represented by an emulation system.

2. Flywheel emulator. The flywheel is emulated by a motor and a frequency converter. The real flywheel generator (or a scaled version) is connected to the emulation motorfrequency converter setup that will behave as the rotating mass.

3. Real flywheel. The emulator is substituted by a real flywheel.

- Fuel cell emulation 
1. Fuel cell emulation. The behavior of a fuel cell is represented by an emulation setup.

2. Real fuel cell. The fuel cell emulator is replaced by a real fuel cell.

[Figure 7 about here.]

As it is mentioned before, it is not possible to define another emulation level including the different emulated resources. Therefore, these emulation proposals are considered inside the frame of the specific emulation.

To conclude, it is interesting to state that researchers always can choose between the different emulation levels proposed. Then, depending on the objectives of the experiment to be performed and the detail of the system variables needed, an emulation level could be selected to accomplish the specifications.

\subsection{Other considerations}

It should be mentioned that the emulation level does not depend on the nature of the grid where the emulator is connected. However, the hardware of the emulator should be adapted depending on the grid nature to perform a proper emulation. As an example, the connection of the elements to the DC Grid, as it is shown in Figure 2, could be substituted by a connection to an AC grid without modifying the emulation level.

The emulators power supply has been shown in all cases represented with a green box for all the emulators. Note that, each of the emulators could include its own individual power supply. Besides, the power supply could also be provided in DC current instead of AC as it is supposed in the different emulation systems.

This document does not include all the systems susceptible of being emulated. For example, a diesel generator could also be emulated properly. The analysis is focused on renewable resources, because they are the most common emulated systems found in the literature. However, if it is desired, the emulation level concept can be easily applied to other technologies.

\section{Emulation literature review}

Based on the review presented in this section, the previous emulation level definition has been made. First, this literature analysis is focused on the platform laboratories where emulators are 
part of the platform structure. Table 1 shows the results of the literature review, classifying the platforms emulators by its corresponding emulation level.

[Table 1 about here.]

In addition to this classification, other emulation test benches have been proposed focused on a single resource. Table 2 shows the classification of these emulators by its corresponding emulation level. Note that, as these devices are emulators that are representing a single resource, they can be classified between emulation levels three and four.

[Table 2 about here.]

The information provided in Tables 1 and 2 is expanded in the appendix section, where a detailed explanation of the laboratories and the emulators found is developed. Next, based on this literature review, several conclusions are drawn:

- In the major part of the laboratories, emulators are combined with real elements, fact that increases the laboratory experimental possibilities, allowing to represent scenarios that could not be possible without an emulator.

- Laboratories are implemented using an AC grid, a DC grid or a combination of both, with emulators connected at both sides.

- The power levels of the elements included in laboratories, either real resources or emulators, range from $100 \mathrm{~W}$ to a few kilowatts.

- One of the main objectives of this type of laboratories is the validation of energy management system strategies.

- The interconnection of several renewable energy sources within the same system is another of the topics analyzed using microgrid laboratory platforms.

- The AC side voltage range depends on the country where the laboratory is installed, according to the local typical voltages. 
- It can be seen that the most common emulation systems are levels three and four, because usually a single emulator is employed to represent a single resource. However, there are examples of emulators representing more than one system, showing that levels one and two are also interesting structures to experiment with.

- Some of the emulators articles are focused only on the development of the emulation device. Whereas in the rest of the reviewed articles, the emulator is used to validate new developments, acting as the real resource. This type of articles, where the emulator is used as a validation tool, are classified in the appendix with the acronym NFE, which stands for Not Focused on the Emulator.

- Emulators representing the same resource, employing the same emulation level, have in common the concept of how the resource is being represented. However, the software and hardware layers of these emulators, could be sufficiently different. For instance, many different PV cell emulators classified into the level 4 of emulation, are built employing various electronic configurations. Of course, depending on the software and hardware employed, the accuracy of the emulation results can vary.

- The hardware layer of the solar emulators reviewed is mainly built based on a DC/DC converter or programmable DC power supply. Different proposals for the structure of the DC/DC converter are shown to improve the transient dynamic response and the efficiency.

- Wind emulators are typically based on a 4-2 emulation level structure, in which the wind resource and the turbine are emulated by a motor controlled by a converter. The current nature and the power rating of the motor included in the emulation structure, depends on the experiment.

- Fuel cell and battery emulators hardware layers are based on DC/DC converters or programmable DC power supplies. The different emulators reviewed show a level 4 emulation structure.

- Load emulators are developed based on a DC/DC converter or a three-phase Voltage Source Converter (VSC). 
- The electric vehicle emulator found in the literature is based on an Induction Machine (IM) applying a defined torque to the EV motor. The emulation levels included are defined for devices connected to microgrids. In this case, the emulator is developed to analyze the operation of the EV, while it is not connected to the grid. Even so, it has been included in the literature review due to the interesting test bench proposal.

- Regarding the software layer of the emulators, different elements are proposed to control the hardware structures: Digital Signal Processors (DSP), dSPACE ${ }^{\circledR}$ systems, Field Programmable Gate Arrays (FPGA), Peripheral Interface Controllers (PIC ${ }^{\circledR}$ ), among other controllers.

- Typically, emulators are custom systems built in the laboratory. However, commercial emulators, to represent the behavior of PV panels and fuel cells, are available.

The previous points summarize the findings of a selection of the emulation structures present in the literature. Of course, other emulator topologies can be developed, based on the testing requirements.

\section{Microgrid platform based on emulators}

In this section, as an example of the possibilities that the emulation systems offer, a complete microgrid including generation, storage and load systems is built only employing emulation devices. It is compounded by three different emulators connected to the same AC grid, a PV generation system emulator, a battery emulator and a load emulator, as it is shown in Figure 8. Figure 9 shows a picture of the setup, where the actual emulators are installed.

Note that, the emulators are connected to a single-phase AC grid, unlike in previous sections, where the description of the different emulation levels is developed considering that emulators are connected to the DC grid. However, as it is mentioned in Section 3, the emulation level is preserved regardless of the nature of the grid to which the emulator is connected. It can also be seen that the PS of the emulators is a single $6 \mathrm{kVA}$ bidirectional converter, for the three emualators.

[Figure 8 about here.] 
[Figure 9 about here.]

Next, a brief description of each emulator behavior is detailed:

- The PV generation [Emulation level 3]. It is emulating the photovoltaic module together with the control converter. The emulator software is considering that the PV module is operated at the Maximum Power Point (MPP). Then, defining the PV characteristics, introducing the system geographical location and loading the scenario irradiance and temperature temporal data, the software emulation part is able to calculate the power generated $P_{M P P}$ by each panel and the total power injected to the grid [10]:

$$
\begin{aligned}
& P_{M P P}=V_{M P P} \cdot I_{M P P} \\
& V_{M P P}=V_{M P P 0} \cdot \frac{\ln (G)}{\ln \left(G_{0}\right)} \cdot\left(1+k_{v} \cdot\left(T_{p}-T_{p, 0}\right)\right) \\
& I_{M P P}=I_{M P P 0} \cdot \frac{G}{G_{0}} \cdot\left(1+k_{i} \cdot\left(T_{p}-T_{p, 0}\right)\right)
\end{aligned}
$$

where, $G$ and $T_{p}$ are the irradiance and the panel temperature (temporal data input) and $V_{M P P 0}, I_{M P P 0}, G_{0}$ and $T_{p, 0}$ are the solar panel parameters at the Standard Test Conditions (STC). Also, it should be mentioned that the whole system is assumed to have zero losses. Anyhow, the efficiency of the inverter could be straightforwardly included in the model.

- Load emulator [Emulation level 2]. It is programed to consume from the grid a programmed active power with a certain power factor $(\mathrm{PF})$ emulating a couple of real loads.

- Battery emulator [Emulation level 3]. The emulator represents the battery together with its corresponding charging/discharging converter. The system is controlled to absorb or inject power when it is required. This implementation does not consider losses within the system. However, the battery and converter efficiencies can be straightforwardly included in the model.

The emulators power rating is $1.5 \mathrm{kVA}$, but the emulation results can be scaled to represent larger power scenarios. Next section shows two different experimental case studies performed on the microgrid, to validate the emulator performance inside the system. The first one is focused on the 
time range of milliseconds, whereas the second one shows the operation of the platform during longer emulations.

\subsection{Microgrid scenario 1 description}

This experiment is focused on the range of hundreds of milliseconds, to demonstrate the operation of the emulators within this time frame. The electrical scheme configuration is shown in Figure 10 and the experimental scenario conditions are:

- Load emulator. It starts consuming $500 \mathrm{~W}$ from the grid with a 0.9 power factor and changes to $1200 \mathrm{~W}$ with the same power factor.

- PV emulator. It is injecting constantly $900 \mathrm{~W}$ due to an irradiance of $600 \mathrm{~W} / \mathrm{m}^{2}$.

- Battery emulator. It is operated to achieve the goal of zero active and reactive power exchange between the main $\mathrm{AC}$ grid and the microgrid during the test.

Figure 11 shows an oscilloscope capture of the system currents. The currents measured are the PV current (magenta), the load current (blue), the battery current (green) and the main grid current (yellow) (see Figure 10 for the color code). It can be observed that during the first part of the test, the microgrid is exchanging zero energy with the grid (the current flowing to the grid is almost zero). This fact is achieved because the PV generation is enough to feed the load, so the excess of power is being stored in the battery. When the load changes its value to a higher one, transiently, it can be seen that the grid feeds it because the PV installation does not produce enough power to do it. However, a few milliseconds later, the battery starts to inject the extra amount of active and reactive power to compensate the extra load consumption, in order to maintain the objective of exchanging zero active and reactive power with the grid.

[Figure 10 about here.]

[Figure 11 about here.]

In this case, the power references for the battery operation are calculated off-line and changed manually during the test, acting as the energy manager would need to do, to maintain the power 
exchange with the grid set to zero. A real energy management system could be included to control the state of charge of the battery, in order to achieve the same goal or others, autonomously.

It can be stated that the employed emulators show a proper behavior during the experiments, both in steady state and during transients, representing the emulated resources accurately.

\subsection{Microgrid scenario 2 description}

This second experiment is designed to show the behavior of the emulators during a longer run test. The electrical scheme configuration is shown in Figure 12 and the experimental scenario conditions are:

- Load emulator. It is consuming active power from the AC grid, following the predefined profile shown in Fig. 13a.

- PV emulator. Based on experimental irradiance measured in field tests, the PV emulator injects to the grid the equivalent amount of power that the a real installation would be injecting under the same conditions. The power profile generated by the PV system software emulator layer is shown in Fig. 13b.

- Battery emulator. It is operated to achieve the goal of zero active power exchange between the grid and the microgrid during the test.

- Test duration: 8 hours compressed in 8 minutes, applying the accelerated emulation with a factor of 60 .

- Power level: The power profiles shown in Fig. 13 are properly adapted to the range of the emulators power hardware layer. The output results are rescaled back to their real magnitudes.

Once the power profiles for the PV array emulator and the load are calculated in the software layer of both emulators, the corresponding hardware layers inject/absorb to/from the AC grid the calculated power. Regarding the battery emulator, its software layer measures the injected power by the PV and the consumed power by the load, and it calculates in real time the power to exchange with the microgrid in order to maintain the zero power flow to the grid. 
Thanks to the emulators, the platform also offers the possibility of accelerating the emulation. Then, a 500 minutes experiment can be carried out in 500 seconds applying an acceleration factor of 60. This experiment could be extended to include results for several days or months, if large temporal data for the PV emulator were available.

[Figure 12 about here.]

[Figure 13 about here.]

Fig. 14 and Fig. 15 show the obtained results of the proposed emulation scenario. Specifically, Fig. 14 shows an oscilloscope capture of the emulators phase currents flowing through the system. The color code for the currents is consistent with the previous scenario (see Figure 12). Note that, as the duration of the experiment has been accelerated, $500 \mathrm{~min}$ are represented in $500 \mathrm{~s}$ (Scope scale: $50 \mathrm{~s} /$ div, 10 divisions). The system currents reflect the power variations imposed by the hardware layers of the emulators, which are tracking the corresponding power profiles. However, this scope capture is not illustrative enough to understand the system behavior, as it does not show the real power flowing through the system.

In order to better understand its operation, the average real power calculation of the power flowing through each of the emulators is shown in Fig. 15. For the sake of clarity, as single phase converters exchange an oscillating power with the $\mathrm{AC}$ grid, only the average component of the power is shown. It can be observed that the hardware layer of the PV and Load emulators is able to inject/absorb power, tracking the power profiles calculated by the software layers. In this experiment, the power reference for the emulators is refreshed every 5 seconds. This value could be reduced to smaller values to improve the power reference tracking. Regarding the battery emulator, during the experiment it is able to compensate the energetic balance with the main grid, absorbing power when there is PV power excess (inverval between 250-300 s) and injecting power when the load consumes more power than the PV generated power (inverval between 25-60 s), in order to maintain the zero exchange power with the grid.

[Figure 14 about here.]

[Figure 15 about here.] 


\subsection{Experimental microgrid discussion}

The microgrid structure presented is based on three different elements, a PV array, a battery and a load emulator of $1.5 \mathrm{kVA}$ rated power each, connected to a single phase AC grid. Other microgrid laboratory proposals, shown in the literature review, include the same resources, either represented only by means of emulators [11] or in a combination of real elements and emulators $[8,12,13,14,15,16]$. The connection to a single-phase system is considered in the proposed platform, due to the reduced power and voltage levels defined for the emulators. Moreover, the connection of generation, storage and loads to a single-phase system could represent a possible microgrid installed in a conventional house or flat, which is interesting to be analyzed, as the power distribution grid could evolve to include this type of systems. According to the literature, laboratories are mainly focused on analyzing hybrid systems combining three-phase AC and DC grids within the same microgrid $[8,13,17,18,19,15,20]$, even considering a single-phase AC side connection $[14,16]$. Other authors, focus their studies either on systems connected to a three-phase AC grid $[7,11,21]$, or to a DC grid [12]. Of course, the laboratory microgrid structure can vary depending on the objectives of the study to be performed.

Regarding the experimental possibilities, the proposed emulation platform includes emulators based on levels 2 and 3 (power level representation of the resources). This type of emulators are not representing the resource variables in detail, but they are behaving equivalently in terms of power flow, being able to carry out experiments related to the highest control levels of the microgrid, as the implementation and testing of energy managers, communications between the different elements, interaction between devices, among others. Based on the literature review, it can be stated that the majority of the laboratories are also developed to implement and study issues related to the energy management system, instead of focusing on a single resource.

Also, as the three emulators of the proposed test bench are based on the same topology, the software layer could be modified to emulate other type of resources. This possibility is also described in $[7,11,12,18,15,20]$, whereas the other laboratories include more specific emulators, designed for representing a single resource.

Focusing on the PV emulation results, among the laboratories that include a PV emulator, only $[11,12,15]$ include a level 3 PV emulator structure, corresponding to an emulator operated 
in power mode. Comparing the obtained results in the second experiment, to the results shown in [11] and [12], it can be seen that the PV emulated power output profile, obtained in all cases, is quite similar, as it is calculated based on real measurements.

Regarding the battery emulator, the majority of the laboratories include real lead acid battery banks, instead of an emulator. Only [7] and [11] include a level 3 battery emulator, as in the

presented microgrid. However, [7] and [11] include the calculation of the battery state of charge, whereas in the proposed microgrid this calculation is not included in the experiments.

The load representation within the microgrid laboratories is carried out using either real systems or emulators. Laboratories $[14,17,15,20]$ use real loads, $[7,11,12,13,18,19]$ and the presented microgrid, include load emulators, and others incorporate a combination of both $[8,16]$.

Focusing on the acceleration capability of the proposed platform, in [12] the experiment time is accelerated to reduce the experimental test duration, as in the second experiment proposed.

In summary, the proposed platform based on emulators include valuable features for the development experiments related with single-phase microgrids, showing similarities and differences compared to other laboratories found in the literature.

\section{Appendix}

In this section, an analysis of the different laboratories and emulators presented in Section 4 and classified in Tables 1 and 2 is performed. Tables 3, 4 and 5 describe the different laboratories found in the literature and Tables from 6 to 15, detail the different emulators proposed for the analyzed resources.

[Table 3 about here.]

[Table 4 about here.]

[Table 5 about here.]

[Table 6 about here.]

[Table 7 about here.] 
[Table 8 about here.]

[Table 9 about here.]

[Table 10 about here.]

[Table 11 about here.]

[Table 12 about here.]

[Table 13 about here.]

[Table 14 about here.]

[Table 15 about here.]

Besides, Fig. 16 shows a world map including the location of the different emulators reviewed, classified by resource. Also, the location of the laboratories is included. Some of the articles do not exactly clarify where the system is installed. In this case, the location is defined based on the affiliation of the corresponding author.

[Figure 16 about here.]

\section{Conclusion}

In this work, a review of the emulation systems available for different resources is developed. First, based on the literature analysis performed the emulation concept is defined, differentiating four emulation levels based on the emulation characteristics. Next, features and possibilities of each of these levels are explained through an example microgrid. Then, the literature review results, of the laboratory platforms and emulation test benches classified by resource and emulation level, are shown. Finally, a small scale microgrid research laboratory platform based on emulators is presented in order to show the proper performance and the possibilities of the emulators. This literature review, along with its classification by emulation levels, could be a useful guide during the design stage of an experiment including emulation systems. 


\section{Acknowledgements}

This work was supported by the Ministerio de Economía y Competitividad under projects IPT-2011-1892-920000, ENE2012-33043 and ENE2013-47296. This research was co-financed by the European Regional Development Fund (ERDF).

\section{References}

[1] R. Lasseter, Microgrids, in: IEEE Power Engineering Society Winter Meeting, 2002., Vol. 1, 2002, pp. 305 - 308 vol.1. doi:10.1109/PESW.2002.985003.

[2] P. Basak, S. Chowdhury, S. Halder nee Dey, S. Chowdhury, A literature review on integration of distributed energy resources in the perspective of control, protection and stability of microgrid. Renewable and Sustainable Energy Reviews., IET renewable energy series. The Institution of Engineering and Technology, 2009.

[3] A. Dobakhshari, S. Azizi, A. Ranjbar, Control of microgrids: Aspects and prospects, in: IEEE International Conference on Networking, Sensing and Control (ICNSC), 2011, 2011, pp. 38-43. doi:10.1109/ICNSC.2011.5874892.

[4] N. Lidula, A. Rajapakse, Microgrids research: A review of experimental microgrids and test systems, Renewable and Sustainable Energy Reviews 15 (1) (2011) 186 - 202. doi:http://dx.doi.org/10.1016/j.rser.2010.09.041.

[5] R. Lasseter, J. Eto, B. Schenkman, J. Stevens, H. Vollkommer, D. Klapp, E. Linton, H. Hurtado, J. Roy, Certs microgrid laboratory test bed, IEEE Transactions on Power Delivery 26 (1) (2011) 325-332. doi:10.1109/TPWRD.2010.2051819.

[6] E. Planas, A. G. de Muro, J. Andreu, I. Kortabarria, I. M. de Alegra, General aspects, hierarchical controls and droop methods in microgrids: A review, Renewable and Sustainable Energy Reviews 17 (0) (2013) 147 - 159. doi:10.1016/j.rser.2012.09.032.

[7] A. Ruiz-Alvarez, A. Colet-Subirachs, F. Alvarez-Cuevas Figuerola, O. Gomis-Bellmunt, A. Sudria-Andreu, Operation of a utility connected microgrid using an iec 61850-based 
multi-level management system, IEEE Transactions on Smart Grid 3 (2) (2012) 858-865. doi:10.1109/TSG.2012.2187222.

[8] V. Salehi, A. Mohamed, A. Mazloomzadeh, O. Mohammed, Laboratory-based smart power system, part i: Design and system development, IEEE Transactions on Smart Grid 3 (3) (2012) 1394-1404. doi:10.1109/TSG.2012.2194518.

[9] T. S. Ustun, C. Ozansoy, A. Zayegh, Recent developments in microgrids and example cases around the world-a review, Renewable and Sustainable Energy Reviews 15 (8) (2011) 4030 4041. doi:http://dx.doi.org/10.1016/j.rser.2011.07.033.

[10] V. Quaschning, Understanding Renewable Energy Systems[Multimédia Multisupport], Understanding Renewable Energy Systems, Earthscan/James \& James, 2005.

[11] M. Marzband, A. Sumper, J. L. Domnguez-Garca, R. Gumara-Ferret, Experimental validation of a real time energy management system for microgrids in islanded mode using a local dayahead electricity market and $\{$ MINLP\}, Energy Conversion and Management 76 (0) (2013) 314 - 322. doi:http://dx.doi.org/10.1016/j.enconman.2013.07.053.

[12] L. Valverde, F. Rosa, C. Bordons, Design, planning and management of a hydrogenbased microgrid, IEEE Transactions on Industrial Informatics 9 (3) (2013) 1398-1404. doi:10.1109/TII.2013.2246576.

[13] M. Sechilariu, B. Wang, F. Locment, Building-integrated microgrid: Advanced local energy management for forthcoming smart power grid communication, Energy and Buildings 59 (0) (2013) 236 - 243. doi:http://dx.doi.org/10.1016/j.enbuild.2012.12.039.

[14] B. Belvedere, M. Bianchi, A. Borghetti, C. Nucci, M. Paolone, A. Peretto, A microcontrollerbased power management system for standalone microgrids with hybrid power supply, IEEE Transactions on Sustainable Energy 3 (3) (2012) 422-431. doi:10.1109/TSTE.2012.2188654.

[15] O. Mohammed, M. A. Nayeem, A. Kaviani, A laboratory based microgrid and distributed generation infrastructure for studying connectivity issues to operational power systems, in: IEEE Power and Energy Society General Meeting, 2010, 2010, pp. 1-6. doi:10.1109/PES.2010.5589693. 
[16] M. Dali, J. Belhadj, X. Roboam, Hybrid solar-wind system with battery storage operating in grid-connected and standalone mode: Control and energy management - experimental investigation, Energy 35 (6) (2010) 2587 - 2595. doi:http://dx.doi.org/10.1016/j.energy.2010.03.005.

[17] B. Wu, J. Liu, F. Zhuo, The micro-grid fast simulation platform exploitation based on pscad, in: Twenty-Sixth Annual IEEE Applied Power Electronics Conference and Exposition (APEC), 2011, 2011, pp. 1737-1742. doi:10.1109/APEC.2011.5744830.

[18] F. Wang, J. Duarte, M. Hendrix, Grid-interfacing converter systems with enhanced voltage quality for microgrid applicatiob: Concept and implementation, IEEE Transactions on Power Electronics 26 (12) (2011) 3501-3513. doi:10.1109/TPEL.2011.2147334.

[19] I. Serban, C. Marinescu, Aggregate load-frequency control of a wind-hydro autonomous microgrid, Renewable Energy $36 \quad(12) \quad(2011) \quad 3345 \quad$ - 3354. doi:http://dx.doi.org/10.1016/j.renene.2011.05.012.

[20] P.-T. Cheng, C.-A. Chen, T.-L. Lee, S.-Y. Kuo, A cooperative imbalance compensation method for distributed-generation interface converters, IEEE Transactions on Industry Applications 45 (2) (2009) 805-815. doi:10.1109/TIA.2009.2013601.

[21] X. Huang, Z. Wang, J. Jiang, Control and load-dispatching strategies for a microgrid with a dc/ac inverter of fixed frequency, International Journal of Electrical Power \& Energy Systems 43 (1) (2012) 1127 - 1136. doi:http://dx.doi.org/10.1016/j.ijepes.2012.06.068.

[22] A. Koran, T. LaBella, J.-S. Lai, High efficiency photovoltaic source simulator with fast response time for solar power conditioning systems evaluation, IEEE Transactions on Power Electronics 29 (3) (2014) 1285-1297. doi:10.1109/TPEL.2013.2262297.

[23] M. de Brito, L. Galotto, L. Sampaio, G. de Azevedo e Melo, C. Canesin, Evaluation of the main mppt techniques for photovoltaic applications, IEEE Transactions on Industrial Electronics 60 (3) (2013) 1156-1167. doi:10.1109/TIE.2012.2198036.

[24] C.-C. Chen, H.-C. Chang, C.-C. Kuo, C.-C. Lin, Programmable energy source emulator for photovoltaic panels considering partial shadow effect, Energy 54 (0) (2013) 174 - 183. doi:http://dx.doi.org/10.1016/j.energy.2013.01.060. 
[25] C.-H. Chang, E.-C. Chang, H.-L. Cheng, A high-efficiency solar array simulator implemented by an llc resonant dc de converter, IEEE Transactions on Power Electronics 28 (6) (2013) 3039-3046. doi:10.1109/TPEL.2012.2205273.

[26] M. D. Piazza, M. Pucci, G. Vitale, Intelligent power conversion system management for photovoltaic generation, Sustainable Energy Technologies and Assessments 2 (0) (2013) 19 30. doi:http://dx.doi.org/10.1016/j.seta.2013.02.003.

[27] D. D. Lu, Q. N. Nguyen, A photovoltaic panel emulator using a buck-boost dc/dc converter and a low cost micro-controller, Solar Energy 86 (5) (2012) 1477 - 1484. doi:http://dx.doi.org/10.1016/j.solener.2012.02.008.

[28] Y. Kim, W. Lee, M. Pedram, N. Chang, Dual-mode power regulator for photovoltaic module emulation, Applied Energy $101 \quad(0) \quad(2013) \quad 730 \quad$ - 739, ¡ce:title¿Sustainable Development of Energy, Water and Environment Systemsi/ce:title. doi:http://dx.doi.org/10.1016/j.apenergy.2012.07.025.

[29] A. Vijayakumari, A. Devarajan, N. Devarajan, Design and development of a model-based hardware simulator for photovoltaic array, International Journal of Electrical Power \& Energy Systems 43 (1) (2012) 40 - 46. doi:http://dx.doi.org/10.1016/j.ijepes.2012.04.049.

[30] R. Kadri, H. Andrei, J.-P. Gaubert, T. Ivanovici, G. Champenois, P. Andrei, Modeling of the photovoltaic cell circuit parameters for optimum connection model and real-time emulator with partial shadow conditions, Energy 42 (1) (2012) 57 - 67, ¡ce:title ¿th World Energy System Conference, \{WESC\} 2010i/ce:title. doi:http://dx.doi.org/10.1016/j.energy.2011.10.018.

[31] R. Kadri, J.-P. Gaubert, G. Champenois, An improved maximum power point tracking for photovoltaic grid-connected inverter based on voltage-oriented control, IEEE Transactions on Industrial Electronics 58 (1) (2011) 66-75. doi:10.1109/TIE.2010.2044733.

[32] A. Koran, K. Sano, R. young Kim, J.-S. Lai, Design of a photovoltaic simulator with a novel reference signal generator and two-stage lc output filter, in: IEEE Energy Conversion Congress and Exposition, 2009. ECCE 2009., 2009, pp. 319-326. doi:10.1109/ECCE.2009.5316190. 
[33] M. C. D. Piazza, G. Vitale, Photovoltaic field emulation including dynamic and partial shadow conditions, Applied Energy $87 \quad(3) \quad(2010) \quad 814 \quad$ - 823. doi:http://dx.doi.org/10.1016/j.apenergy.2009.09.036.

[34] F. Martinez, L. C. Herrero, S. de Pablo, Open loop wind turbine emulator, Renewable Energy 63 (0) (2014) 212 - 221. doi:http://dx.doi.org/10.1016/j.renene.2013.09.019.

[35] A. Egea-Alvarez, F. Bianchi, A. Junyent-Ferre, G. Gross, O. Gomis-Bellmunt, Voltage control of multiterminal vsc-hvdc transmission systems for offshore wind power plants: Design and implementation in a scaled platform, IEEE Transactions on Industrial Electronics 60 (6) (2013) 2381-2391. doi:10.1109/TIE.2012.2230597.

[36] C.-H. Lin, Recurrent modified elman neural network control of $\{\mathrm{PM}\}$ synchronous generator system using wind turbine emulator of $\{\mathrm{PM}\}$ synchronous servo motor drive, International Journal of Electrical Power \& Energy Systems 52 (0) (2013) 143 - 160. doi:http://dx.doi.org/10.1016/j.ijepes.2013.03.021.

[37] Y. Zou, M. Elbuluk, Y. Sozer, Stability analysis of maximum power point tracking (mppt) method in wind power systems, IEEE Transactions on Industry Applications 49 (3) (2013) 1129-1136. doi:10.1109/TIA.2013.2251854.

[38] T. H. Nguyen, D.-C. Lee, Advanced fault ride-through technique for pmsg wind turbine systems using line-side converter as statcom, IEEE Transactions on Industrial Electronics 60 (7) (2013) 2842-2850. doi:10.1109/TIE.2012.2229673.

[39] A. Abdelkafi, A. Masmoudi, L. Krichen, Experimental investigation on the performance of an autonomous wind energy conversion system, International Journal of Electrical Power \& Energy Systems 44 (1) (2013) 581 - 590. doi:http://dx.doi.org/10.1016/j.ijepes.2012.08.017.

[40] A. Urtasun, P. Sanchis, I. S. Martn, J. Lpez, L. Marroyo, Modeling of small wind turbines based on $\{\mathrm{PMSG}\}$ with diode bridge for sensorless maximum power tracking, Renewable Energy 55 (0) (2013) 138 - 149. doi:http://dx.doi.org/10.1016/j.renene.2012.12.035. 
[41] D. Atkinson, G. Pannell, W. Cao, B. Zahawi, T. Abeyasekera, M. Jovanovic, A doubly-fed induction generator test facility for grid fault ride-through analysis, IEEE Instrumentation Measurement Magazine 15 (6) (2012) 20-27. doi:10.1109/MIM.2012.6365539.

[42] D. Ramirez, S. Martinez, F. Blazquez, C. Carrero, Use of $\{$ STATCOM $\}$ in wind farms with fixed-speed generators for grid code compliance, Renewable Energy 37 (1) (2012) 202 - 212. doi:http://dx.doi.org/10.1016/j.renene.2011.06.018.

[43] A. Masmoudi, L. Krichen, A. Ouali, Voltage control of a variable speed wind turbine connected to an isolated load: Experimental study, Energy Conversion and Management 59 (0) (2012) 19 - 26. doi:http://dx.doi.org/10.1016/j.enconman.2012.02.002.

[44] R. Sharma, U. Madawala, The concept of a smart wind turbine system, Renewable Energy 39 (1) (2012) 403 - 410. doi:http://dx.doi.org/10.1016/j.renene.2011.08.051.

[45] D. Ramirez, S. Martinez, C. Carrero, C. A. Platero, Improvements in the grid connection of renewable generators with full power converters, Renewable Energy 43 (0) (2012) 90 - 100. doi:http://dx.doi.org/10.1016/j.renene.2011.11.054.

[46] I. Serban, C. Marinescu, A sensorless control method for variablespeed small wind turbines, Renewable Energy $43 \quad$ (0) (2012) $256 \quad$ - 266. doi:http://dx.doi.org/10.1016/j.renene.2011.12.018.

[47] J. Arribas, C. Veganzones, F. Blazquez, C. Platero, D. Ramirez, S. Martinez, J. Sanchez, N. Herrero Martinez, Computer-based simulation and scaled laboratory bench system for the teaching and training of engineers on the control of doubly fed induction wind generators, IEEE Transactions on Power Systems 26 (3) (2011) 1534-1543. doi:10.1109/TPWRS.2010.2083703.

[48] S. Roy, Reduction of voltage dynamics in isolated wind-diesel units susceptible to gusting, IEEE Transactions on Sustainable Energy 1 (2) (2010) 84-91. doi:10.1109/TSTE.2010.2050346. 
[49] F. Poitiers, T. Bouaouiche, M. Machmoum, Advanced control of a doubly-fed induction generator for wind energy conversion, Electric Power Systems Research 79 (7) (2009) 1085 - 1096. doi:http://dx.doi.org/10.1016/j.epsr.2009.01.007.

[50] M. E. Mokadem, V. Courtecuisse, C. Saudemont, B. Robyns, J. Deuse, Experimental study of variable speed wind generator contribution to primary frequency control, Renewable Energy 34 (3) (2009) 833 - 844. doi:http://dx.doi.org/10.1016/j.renene.2008.04.033.

[51] R. Cardenas, R. Pea, P. Wheeler, J. Clare, G. Asher, Control of the reactive power supplied by a wecs based on an induction generator fed by a matrix converter, IEEE Transactions on Industrial Electronics 56 (2) (2009) 429-438. doi:10.1109/TIE.2008.924031.

[52] R. Cardenas, R. Pena, J. Clare, G. Asher, J. Proboste, Mras observers for sensorless control of doubly-fed induction generators, IEEE Transactions on Power Electronics 23 (3) (2008) 1075-1084. doi:10.1109/TPEL.2008.921189.

[53] H. Camblong, I. M. de Alegria, M. Rodriguez, G. Abad, Experimental evaluation of wind turbines maximum power point tracking controllers, Energy Conversion and Management 47 (18-19) (2006) 2846 - 2858. doi:http://dx.doi.org/10.1016/j.enconman.2006.03.033.

[54] F. J. Lin, L. T. Teng, P. H. Shieh, Y. F. Li, Intelligent controlled-wind-turbine emulator and induction-generator system using rbfn, Electric Power Applications, IEE Proceedings - 153 (4) (2006) 608-618.

[55] H. Li, M. Steurer, K. L. Shi, S. Woodruff, D. Zhang, Development of a unified design, test, and research platform for wind energy systems based on hardware-in-the-loop realtime simulation, IEEE Transactions on Industrial Electronics 53 (4) (2006) 1144-1151. doi:10.1109/TIE.2006.878319.

[56] R. Cardenas, R. Pena, Sensorless vector control of induction machines for variable-speed wind energy applications, IEEE Transactions on Energy Conversion 19 (1) (2004) 196-205. doi:10.1109/TEC.2003.821863.

[57] C. Kana, M. Thamodharan, A. Wolf, System management of a wind-energy converter, IEEE Transactions on Power Electronics 16 (3) (2001) 375-381. doi:10.1109/63.923770. 
[58] P. Battaiotto, R. Mantz, P. Puleston, A wind turbine emulator based on a dual $\{\mathrm{DSP}\}$ processor system, Control Engineering Practice 4 (9) (1996) 1261 - 1266. doi:http://dx.doi.org/10.1016/0967-0661(96)00132-3.

[59] C. de Beer, P. Barendse, A. Khan, Development of an ht pem fuel cell emulator using a multiphase interleaved dc dc converter topology, IEEE Transactions on Power Electronics 28 (3) (2013) 1120-1131. doi:10.1109/TPEL.2012.2208481.

[60] F. Gao, B. Blunier, D. Chrenko, D. Bouquain, A. Miraoui, Multirate fuel cell emulation with spatial reduced real-time fuel cell modeling, IEEE Transactions on Industry Applications 48 (4) (2012) 1127-1135. doi:10.1109/TIA.2012.2198909.

[61] C. Restrepo, C. Ramos-Paja, R. Giral, J. Calvente, A. Romero, Fuel cell emulator for oxygen excess ratio estimation on power electronics applications, Computers \& Electrical Engineering 38 (4) (2012) 926 - 937. doi:http://dx.doi.org/10.1016/j.compeleceng.2012.02.012.

[62] T. Bjaziv, Z. Ban, M. Milanovic, Modeling of current mode controlled boost converter supplied by fuel cell suitable for controller design purposes, Journal of Power Sources 198 (0) (2012) 203 - 217. doi:http://dx.doi.org/10.1016/j.jpowsour.2011.09.079.

[63] F. Gao, B. Blunier, M. Simoes, A. Miraoui, Pem fuel cell stack modeling for real-time emulation in hardware-in-the-loop applications, IEEE Transactions on Energy Conversion 26 (1) (2011) 184-194. doi:10.1109/TEC.2010.2053543.

[64] G. Marsala, M. Pucci, G. Vitale, M. Cirrincione, A. Miraoui, A prototype of a fuel cell \{PEM\} emulator based on a buck converter, Applied Energy 86 (10) (2009) 2192 - 2203. doi:http://dx.doi.org/10.1016/j.apenergy.2008.12.028.

[65] T. Zhou, B. Francois, M. el Hadi Lebbal, S. Lecoeuche, Real-time emulation of a hydrogenproduction process for assessment of an active wind-energy conversion system, IEEE Transactions on Industrial Electronics 56 (3) (2009) 737-746. doi:10.1109/TIE.2008.2007048.

[66] W. C. Lee, D. Drury, Development of a hardware-in-the-loop simulation system for testing cell balancing circuits, IEEE Transactions on Power Electronics 28 (12) (2013) 5949-5959. doi:10.1109/TPEL.2013.2256799. 
[67] O. Konig, G. Gregorcic, S. Jakubek, Model predictive control of a dc-dc converter for battery emulation, Control Engineering Practice 21 (4) (2013) 428 - 440. doi:http://dx.doi.org/10.1016/j.conengprac.2012.12.009.

[68] O. Konig, C. Hametner, G. Prochart, S. Jakubek, Battery emulation for power-hil using local model networks and robust impedance control, IEEE Transactions on Industrial Electronics 61 (2) (2014) 943-955. doi:10.1109/TIE.2013.2253070.

[69] H. Dai, X. Zhang, X. Wei, Z. Sun, J. Wang, F. Hu, Cell-bms validation with a hardware-in-the-loop simulation of lithium-ion battery cells for electric vehicles, International Journal of Electrical Power \& Energy Systems 52 (0) (2013) 174 - 184. doi:http://dx.doi.org/10.1016/j.ijepes.2013.03.037.

[70] A. D. Bernardinis, S. Butterbach, R. Lallemand, A. Jeunesse, G. Coquery, P. Aubin, Double resonant isolated converter for battery charger with fast switching semiconductors used in hybrid electric shunting locomotive, Electric Power Systems Research 92 (0) (2012) 43 - 49. doi:http://dx.doi.org/10.1016/j.epsr.2012.04.020.

[71] E. Duran, J. Andujar, F. Segura, A. Barragan, A high-flexibility dc load for fuel cell and solar arrays power sources based on dc-dc converters, Applied Energy 88 (5) (2011) 1690 - 1702. doi:http://dx.doi.org/10.1016/j.apenergy.2010.11.002.

[72] X. Zhang, C. C. Mi, A. Masrur, D. Daniszewski, Wavelet-transform-based power management of hybrid vehicles with multiple on-board energy sources including fuel cell, battery and ultracapacitor, Journal of Power Sources 185 (2) (2008) 1533 - 1543. doi:http://dx.doi.org/10.1016/j.jpowsour.2008.08.046.

[73] Y. Rao, M. Chandorkar, Real-time electrical load emulator using optimal feedback control technique, IEEE Transactions on Industrial Electronics 57 (4) (2010) 1217-1225. doi:10.1109/TIE.2009.2037657.

[74] E. Adzic, M. Adzic, V. Katic, D. Marcetic, N. Celanovic, Development of high-reliability ev and hev im propulsion drive with ultra-low latency hil environment, IEEE Transactions on Industrial Informatics 9 (2) (2013) 630-639. doi:10.1109/TII.2012.2222649. 


\section{List of Figures}

1 Photovoltaic emulator concept . . . . . . . . . . . . . . . . . 30

2 Microgrid base electrical layout . . . . . . . . . . . . . . . . . . 31

3 Level 1 - Global emulation scheme . . . . . . . . . . . . . . . . . . . . . . 32

4 Level 2 - Aggregated emulation scheme . . . . . . . . . . . . . . . . . . . 33

5 Level 3 - Resource emulation scheme . . . . . . . . . . . . . . . . . . . . . 34

6 Level 4 -Specific emulation scheme . . . . . . . . . . . . . . . . . . . 35

7 Level 4 - Specific emulation scheme for each resource . . . . . . . . . . . . . 36

8 Scheme and physical implementation of the platform . . . . . . . . . . . . 37

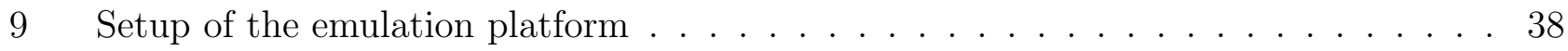

10 Scenario 1 - Scheme and physical implementation of the platform . . . . . . . . . 39

11 Currents flowing through the emulators - PV (magenta) - Load (blue) - Battery (green) - Grid (yellow) . . . . . . . . . . . . . . . . . . 40 40

12 Scenario 2 - Scheme and physical implementation of the platform . . . . . . . . . 41

13 Power profiles for the PV and load emulator . . . . . . . . . . . . . . . . . . . . . 42

14 Currents flowing through the emulators - PV (magenta) - Load (blue) - Battery (green) . . . . . . . . . . . . . . . . . . . 43

15 Power flowing through the emulators - PV (magenta) - Load (blue) - Battery (green) 44

16 Laboratories and emulators world map . . . . . . . . . . . . . . . . 45 


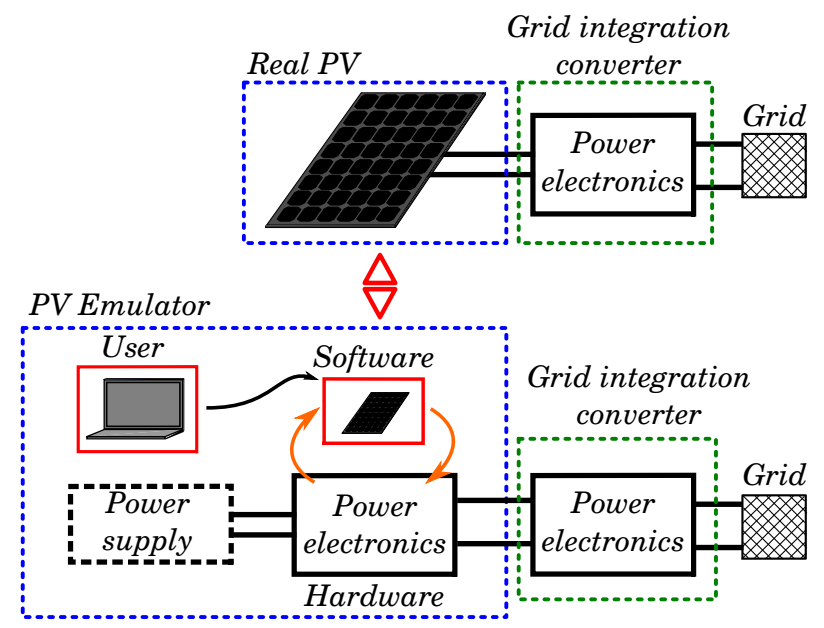

Figure 1: Photovoltaic emulator concept 


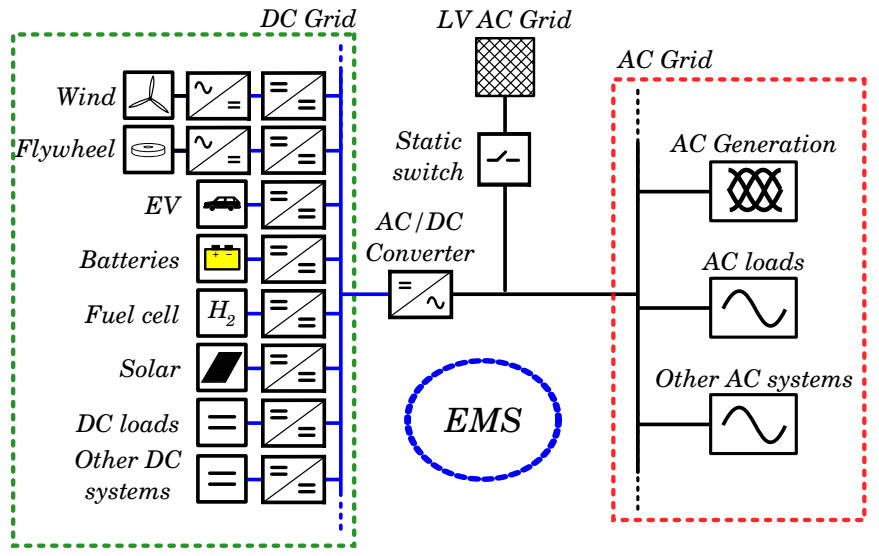

Figure 2: Microgrid base electrical layout 


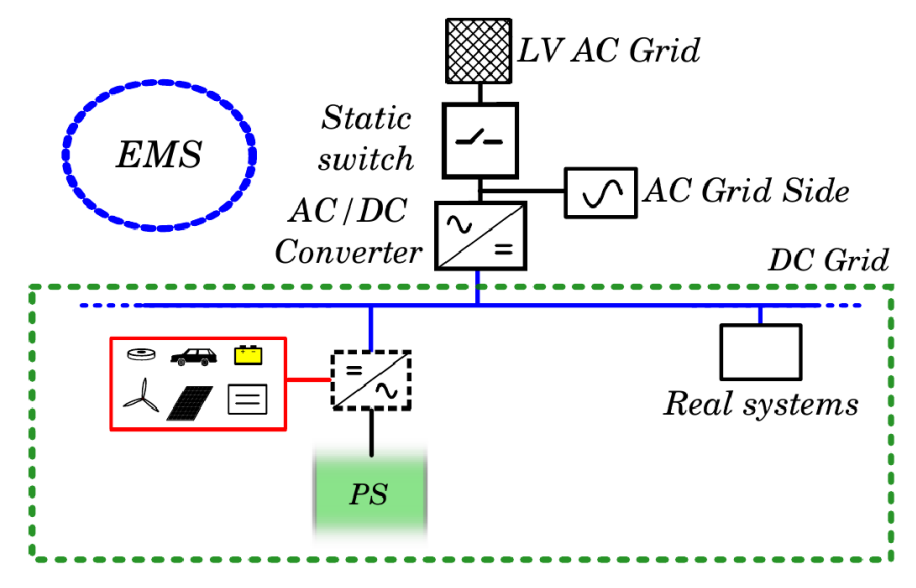

Figure 3: Level 1 - Global emulation scheme 


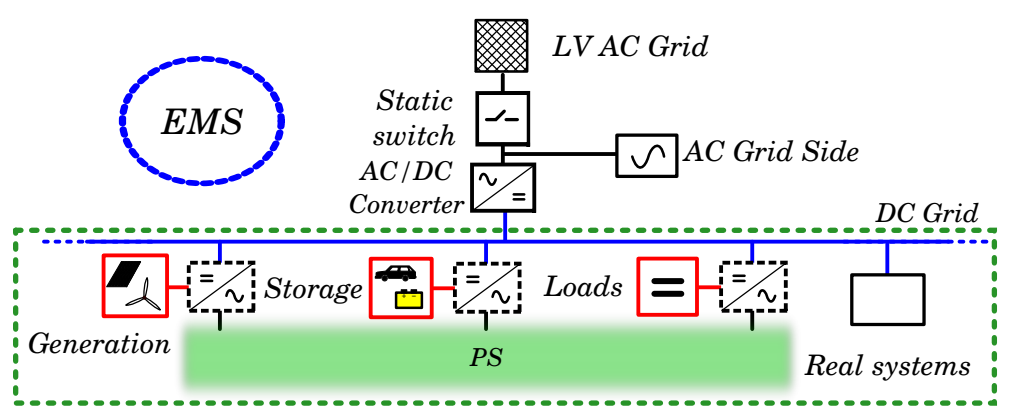

Figure 4: Level 2 - Aggregated emulation scheme 


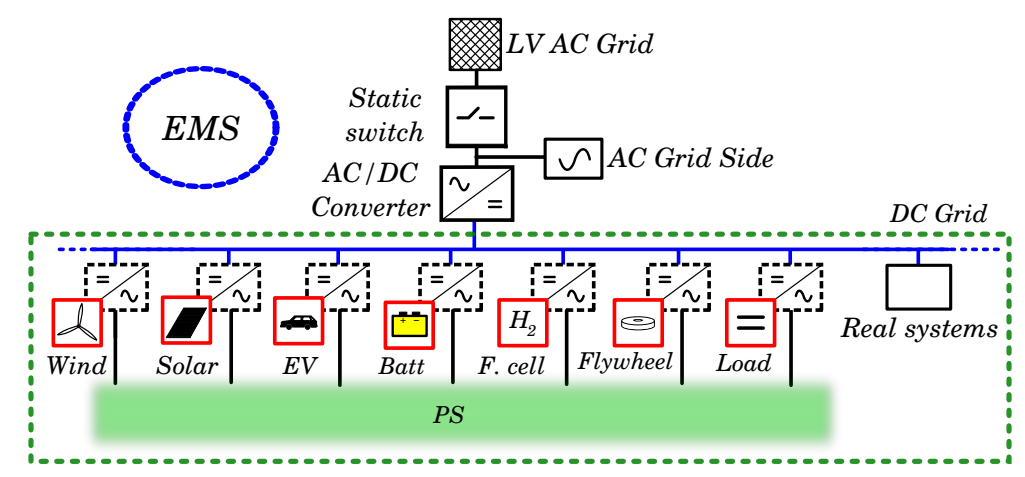

Figure 5: Level 3 - Resource emulation scheme 


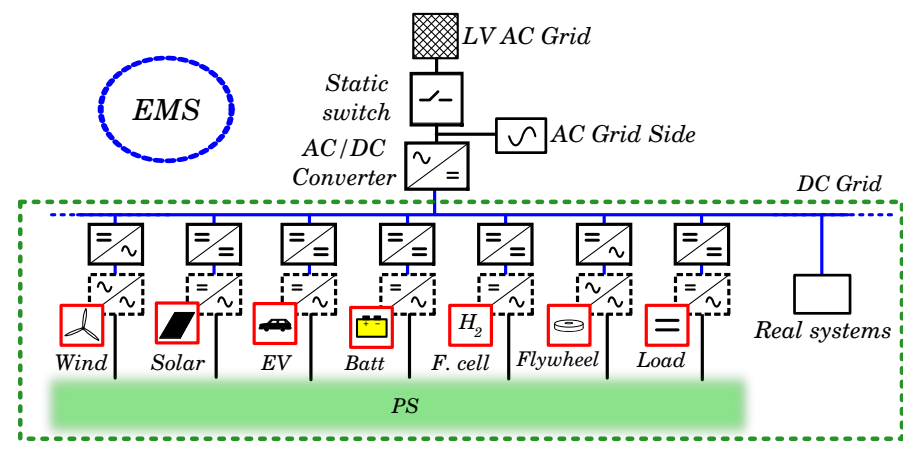

Figure 6: Level 4 - Specific emulation scheme 


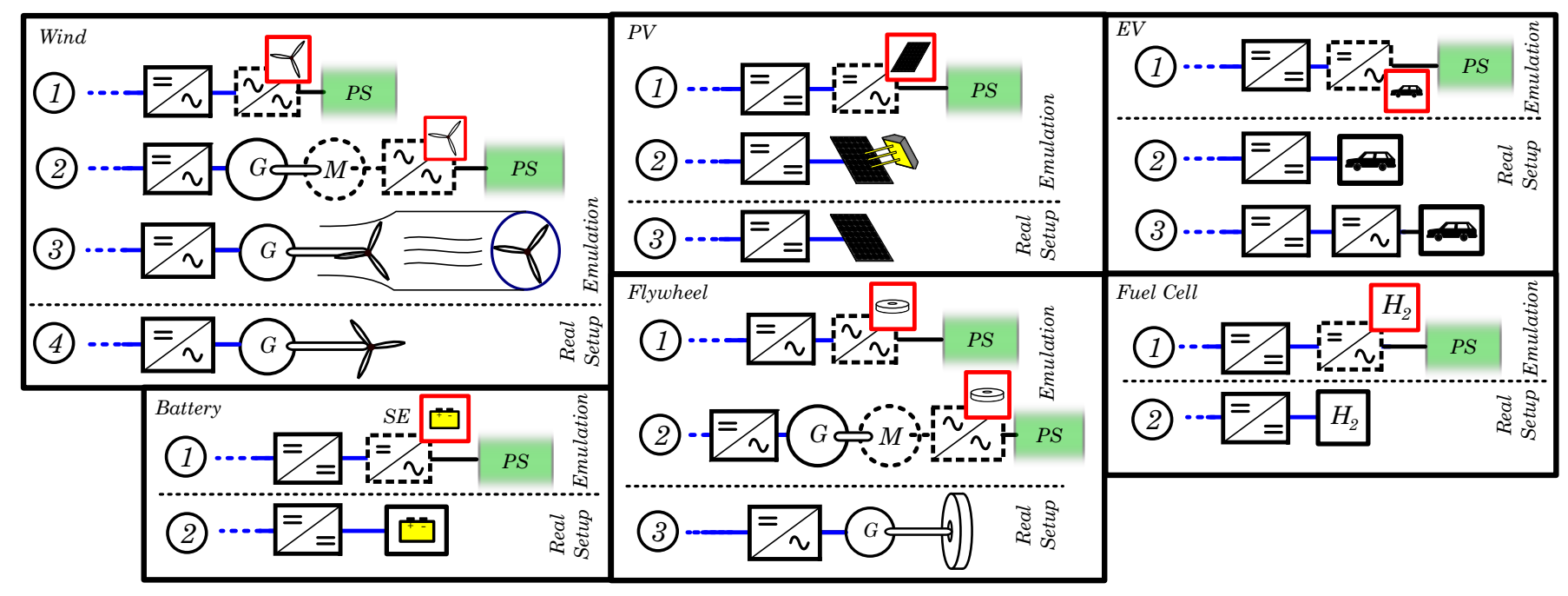

Figure 7: Level 4 - Specific emulation scheme for each resource 


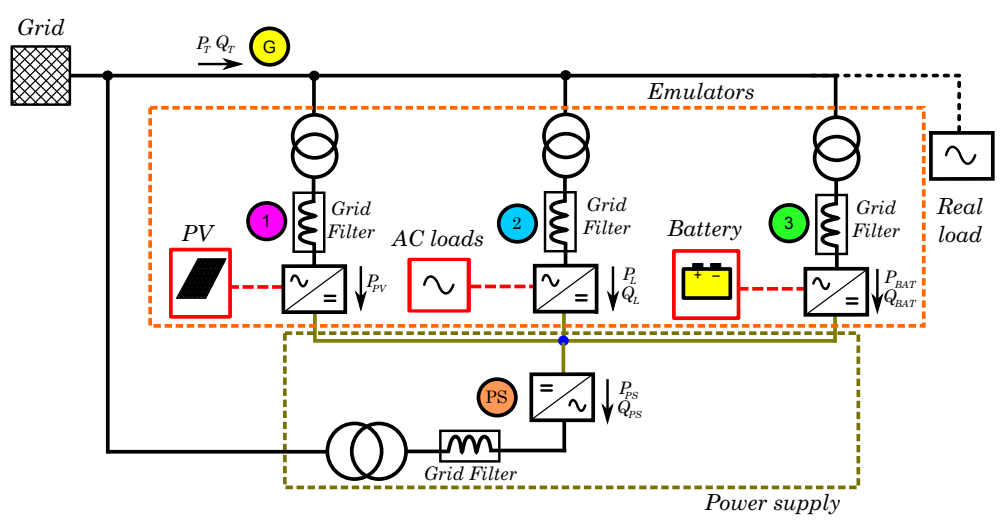

Figure 8: Scheme and physical implementation of the platform 


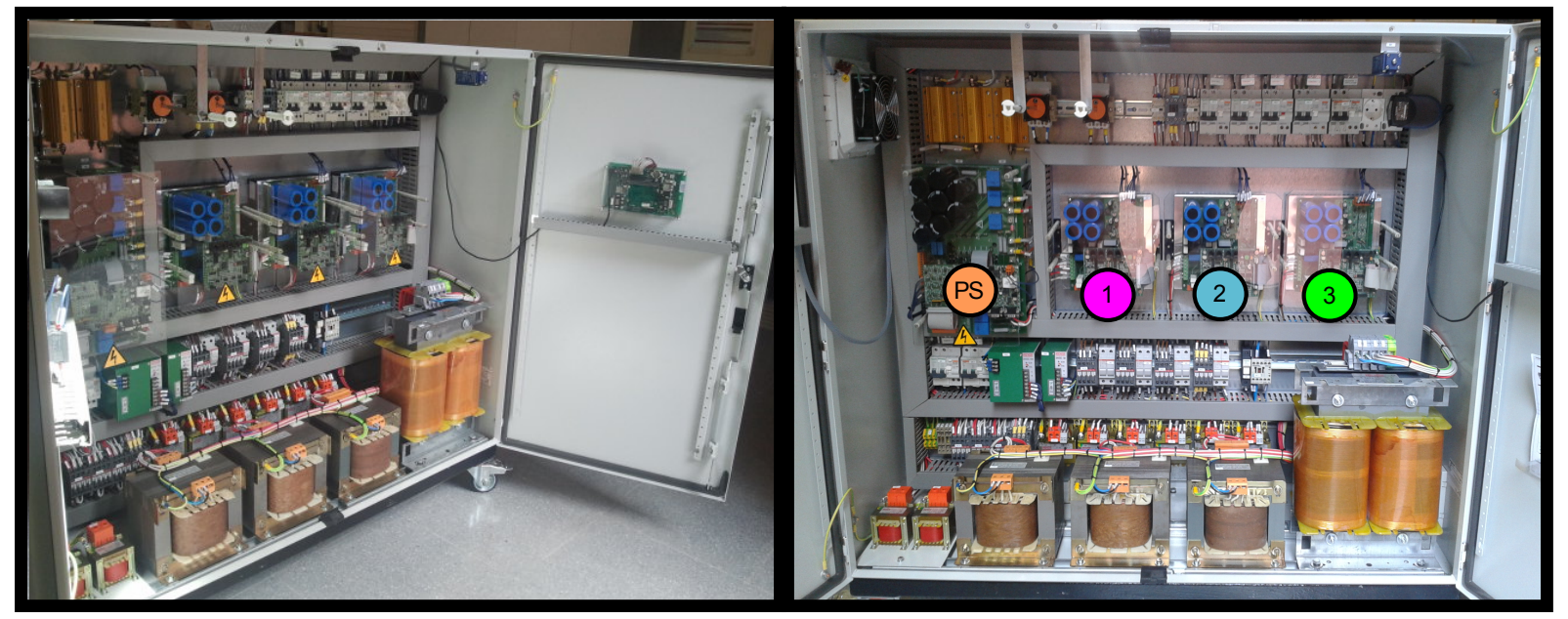

Figure 9: Setup of the emulation platform 


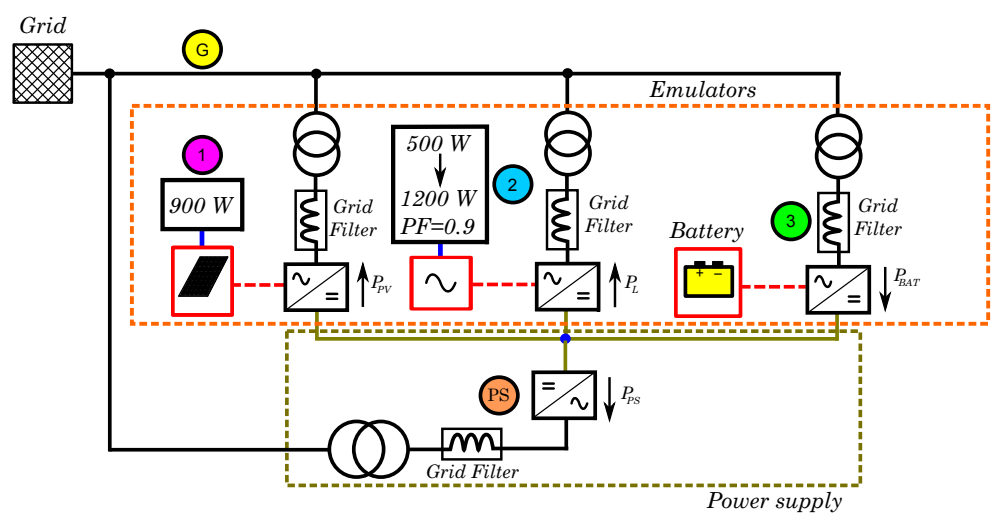

Figure 10: Scenario 1 - Scheme and physical implementation of the platform 


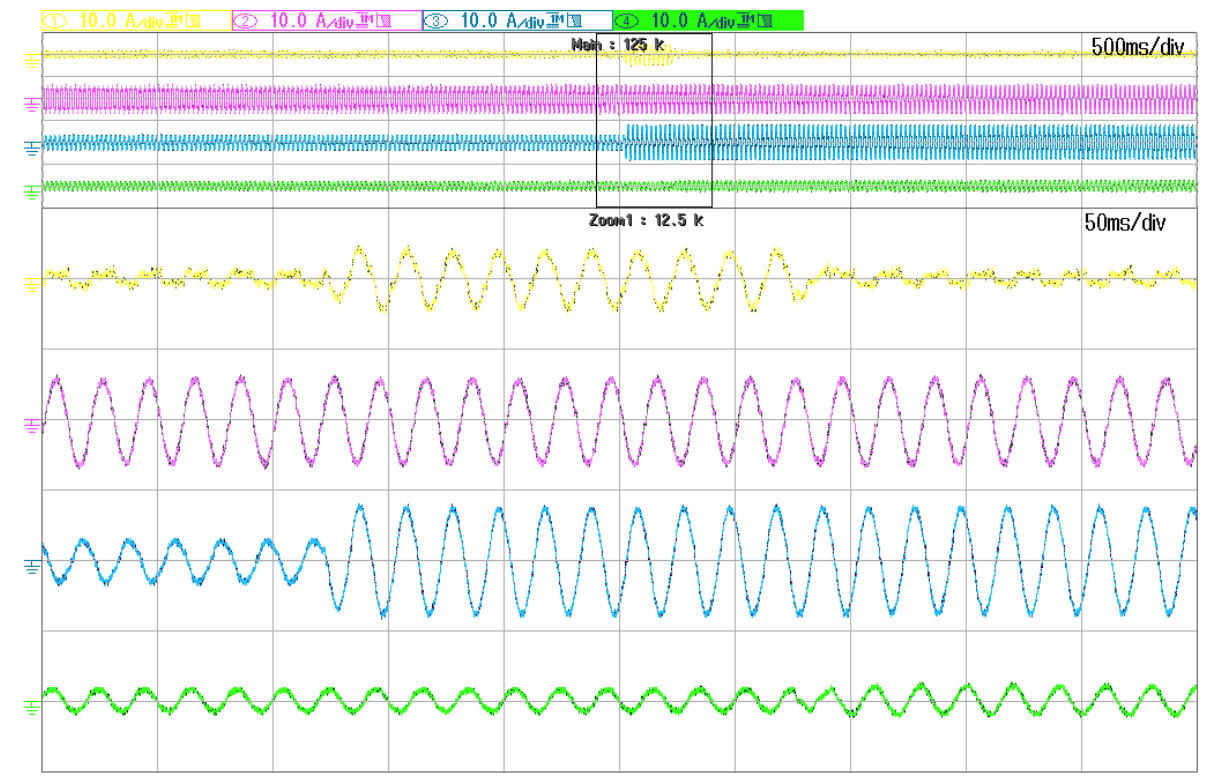

Figure 11: Currents flowing through the emulators - PV (magenta) - Load (blue) - Battery (green) - Grid (yellow) 


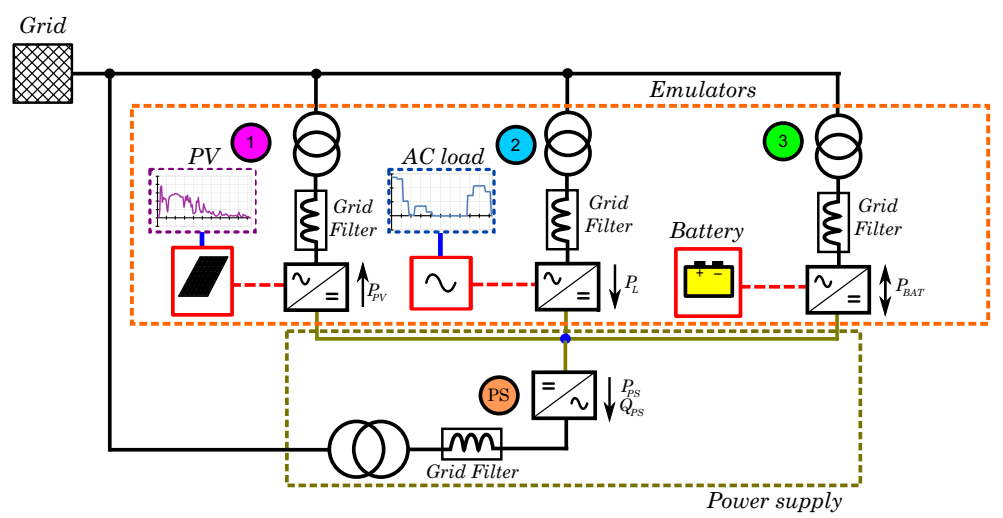

Figure 12: Scenario 2 - Scheme and physical implementation of the platform 


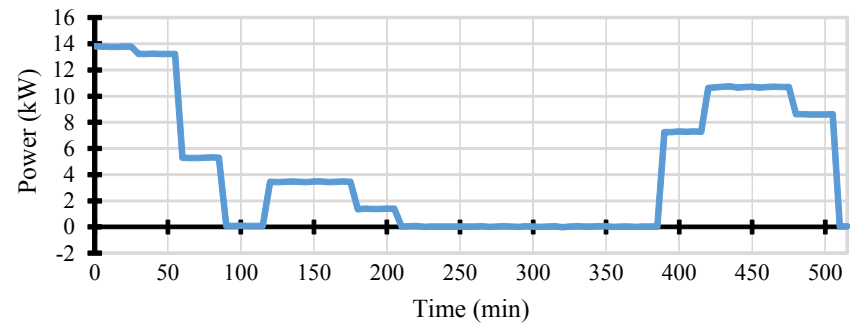

(a) Load emulator power profile

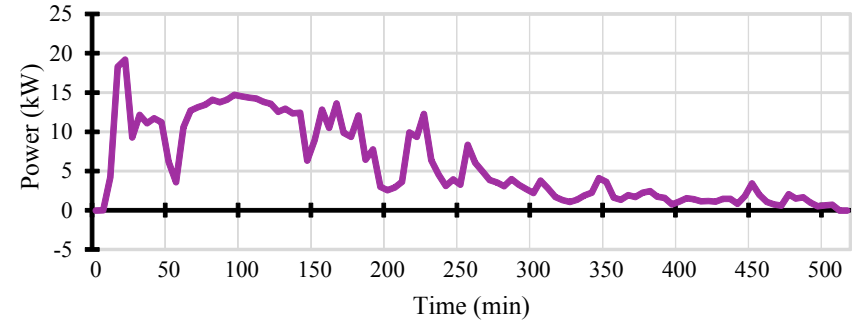

(b) PV emulator power profile

Figure 13: Power profiles for the PV and load emulator 


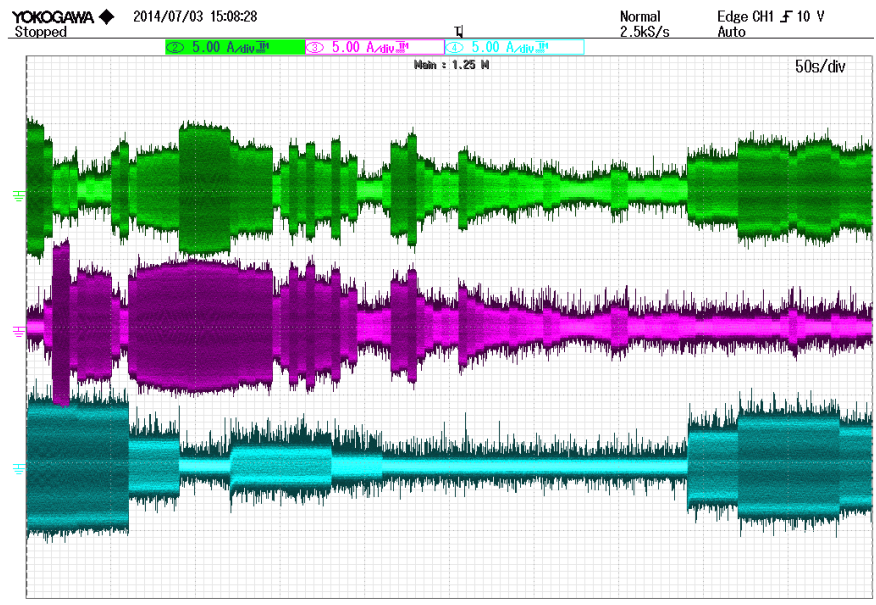

Figure 14: Currents flowing through the emulators - PV (magenta) - Load (blue) - Battery (green) 


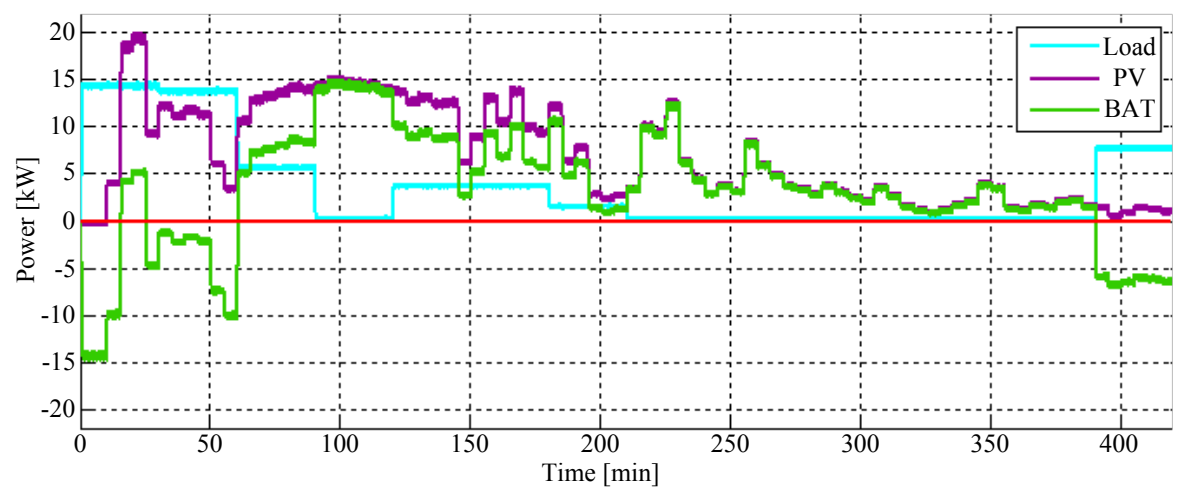

Figure 15: Power flowing through the emulators - PV (magenta) - Load (blue) - Battery (green) 


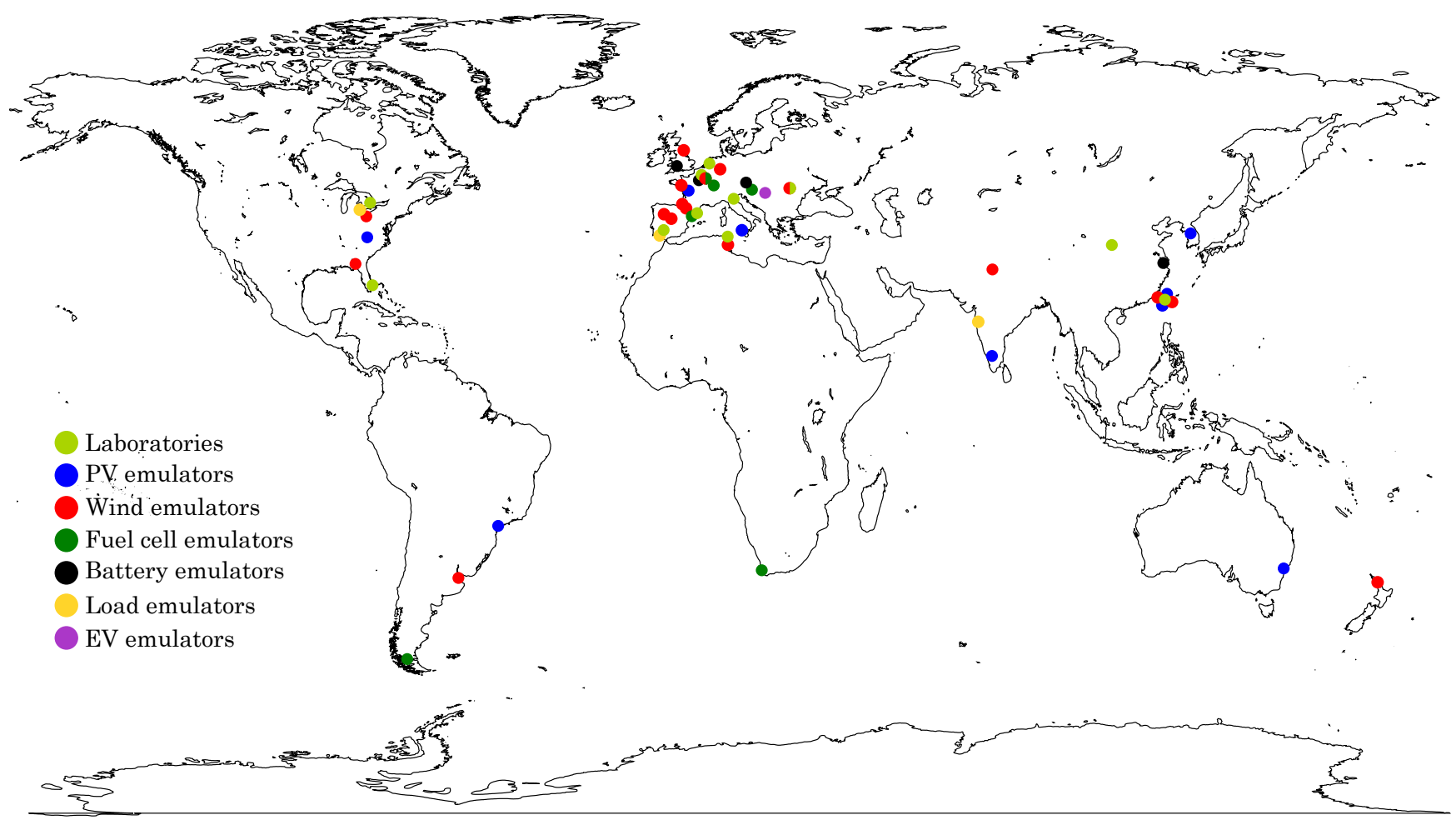

Figure 16: Laboratories and emulators world map 


\section{List of Tables}

1 Classification by emulation levels of the laboratory platform emulators found in the literature . . . . . . . . . . . . . . . . . . . . 4 47

2 Classification by emulation levels of the emulation test benches found in the literature 48

3 Laboratories review - Part I . . . . . . . . . . . . . . . . . . . . . . . . . 49

4 Laboratories review - Part II . . . . . . . . . . . . . . . . . . . . 50

5 Laboratories review - Part III . . . . . . . . . . . . . . . . . . . 51

6 Solar emulator review - Part I . . . . . . . . . . . . . . . . . . . . 52

7 Solar emulator review - Part II . . . . . . . . . . . . . . . . . . 53

8 Wind emulator review - Part I . . . . . . . . . . . . . . . . . . 54

9 Wind emulator review - Part II . . . . . . . . . . . . . . . . . . . . . . 55

10 Wind emulator review - Part III . . . . . . . . . . . . . . . . . . 56

11 Wind emulator review - Part IV . . . . . . . . . . . . . . . . . . 57

12 Fuel cell emulator review . . . . . . . . . . . . . . . . . . . . . . . 58

13 Battery emulator review . . . . . . . . . . . . . . . . . 59

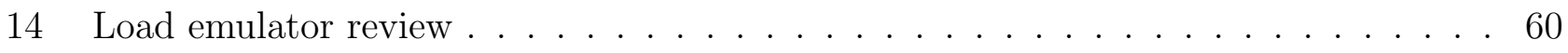

15 EV emulator review . . . . . . . . . . . . . . . . . . 6 61 
Table 1: Classification by emulation levels of the laboratory platform emulators found in the literature

\begin{tabular}{cccccccc}
\hline Reference & Wind & PV & Fuel Cell & Battery & EV & Flywheel & Load demand \\
\hline$[7]$ & 3 & - & - & 3 & - & - & 3 \\
\hline$[8]$ & - & 4 & 4 & Real & - & - & Real, 3 \\
\hline$[11]$ & 3 & 3 & - & 3 & - & - & 3 \\
\hline$[12]$ & 3 & 3 & Real & Real & - & - & 3 \\
\hline$[13]$ & - & Real & - & Real & - & - & 2 \\
\hline$[14]$ & - & 4 & Real & Real & - & - & Real \\
\hline$[21]$ & - & - & Real & Real & - & - & 3 \\
\hline$[17]$ & 3 & 3 & - & - & - & - & Real \\
\hline$[18]$ & 1 & 1 & 1 & 1 & - & - & 3 \\
\hline$[19]$ & 4 & - & - & Real & - & - & 3 \\
\hline$[15]$ & 4 & 3 & 3 & Real & - & 4 & Real \\
\hline$[16]$ & 4 & 4 & - & Real & - & - & Real, 3 \\
\hline$[20]$ & 2 & 2 & 2 & - & - & - & Real
\end{tabular}


Table 2: Classification by emulation levels of the emulation test benches found in the literature

\begin{tabular}{lcl}
\hline Emulated resource & Level 3 & Level 4 \\
\hline \multirow{2}{*}{ Solar power } & - & {$[22],[23],[24],[25],[26],[27],[28]$,} \\
& & {$[29],[30],[31],[32],[33]$} \\
\hline & & {$[34],[35],[36],[37],[38],[39],[40]$,} \\
Wind power & - & {$[41],[42],[43],[44],[45],[46],[47]$,} \\
& & {$[48],[49],[50],[51],[52],[53],[54]$,} \\
& - & {$[59],[56],[57],[58]$} \\
\hline Fuel cell & - & {$[66],[67],[61],[62],[63],[69],[60],[65]$} \\
\hline Battery & {$[71],[72]$} & {$[73]$} \\
\hline Load & - & {$[74]$} \\
\hline Electric vehicle & &
\end{tabular}




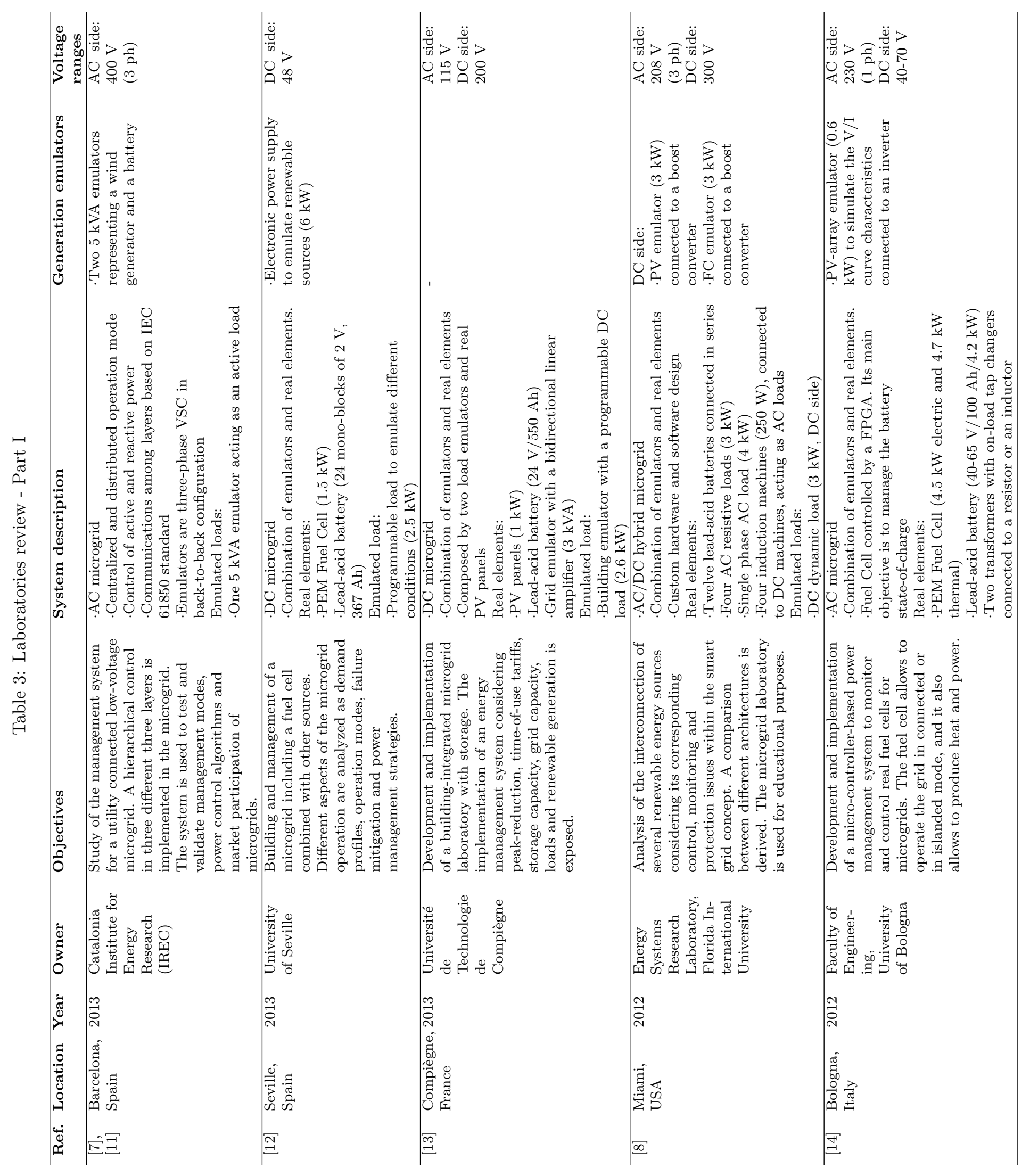




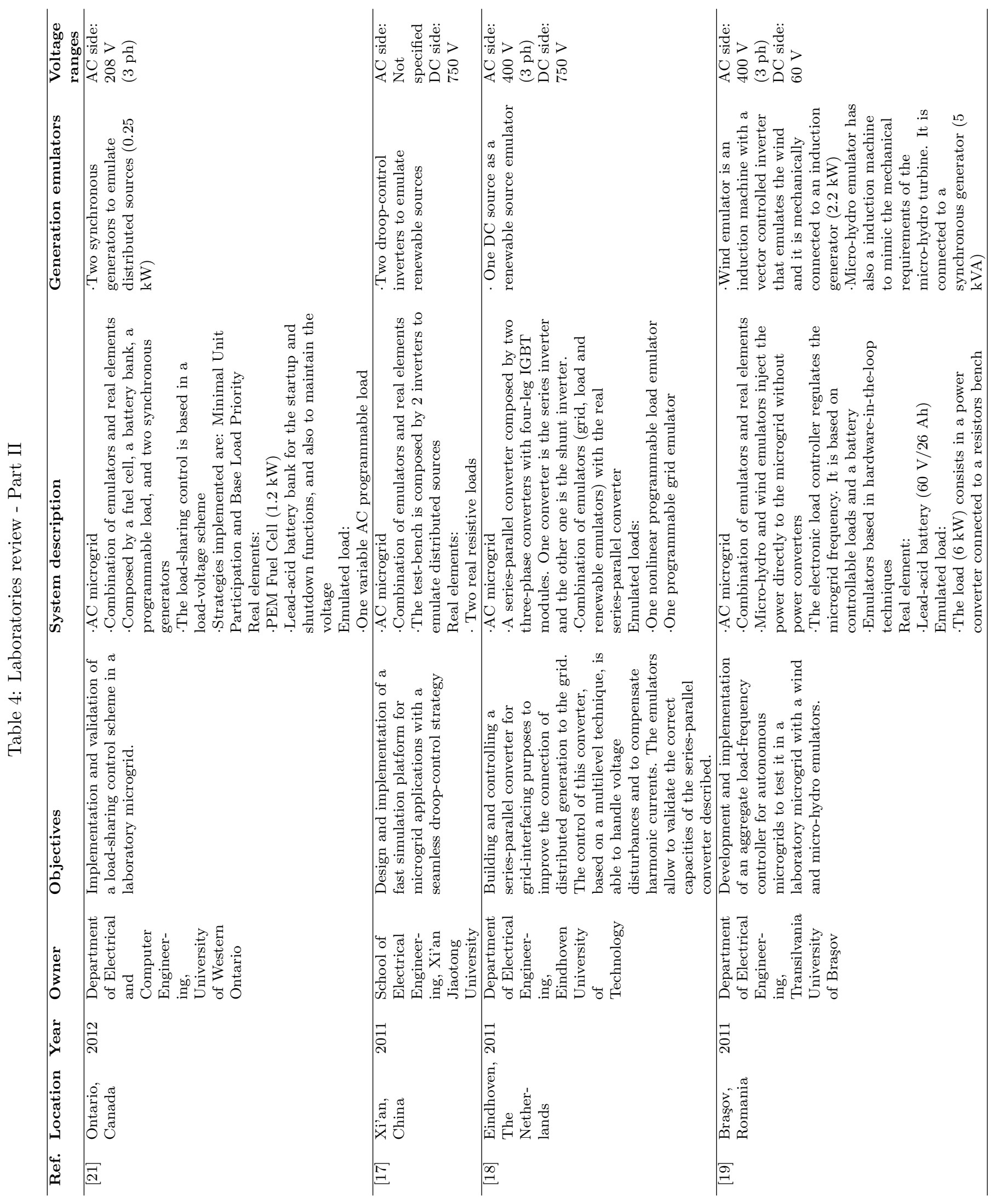




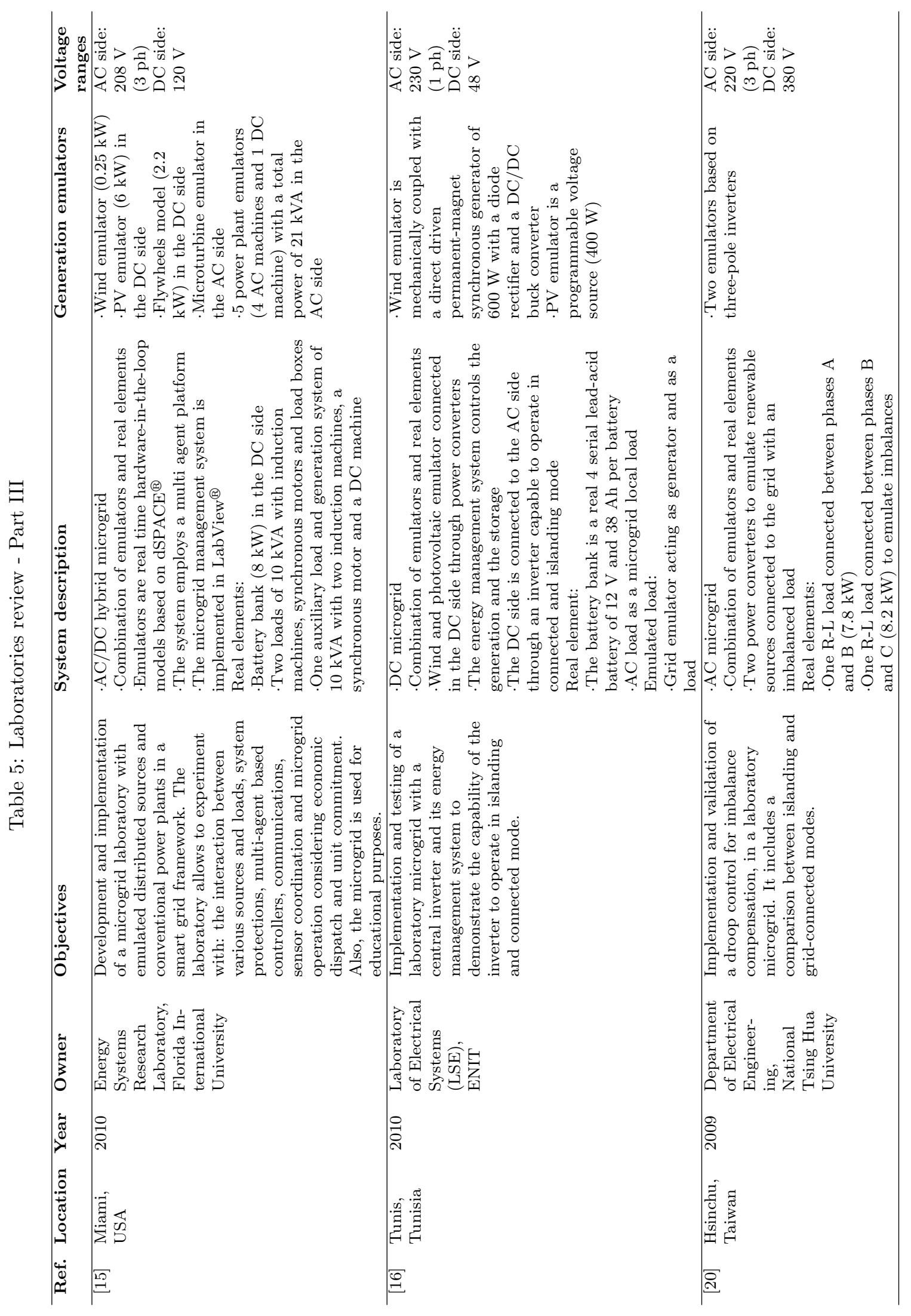




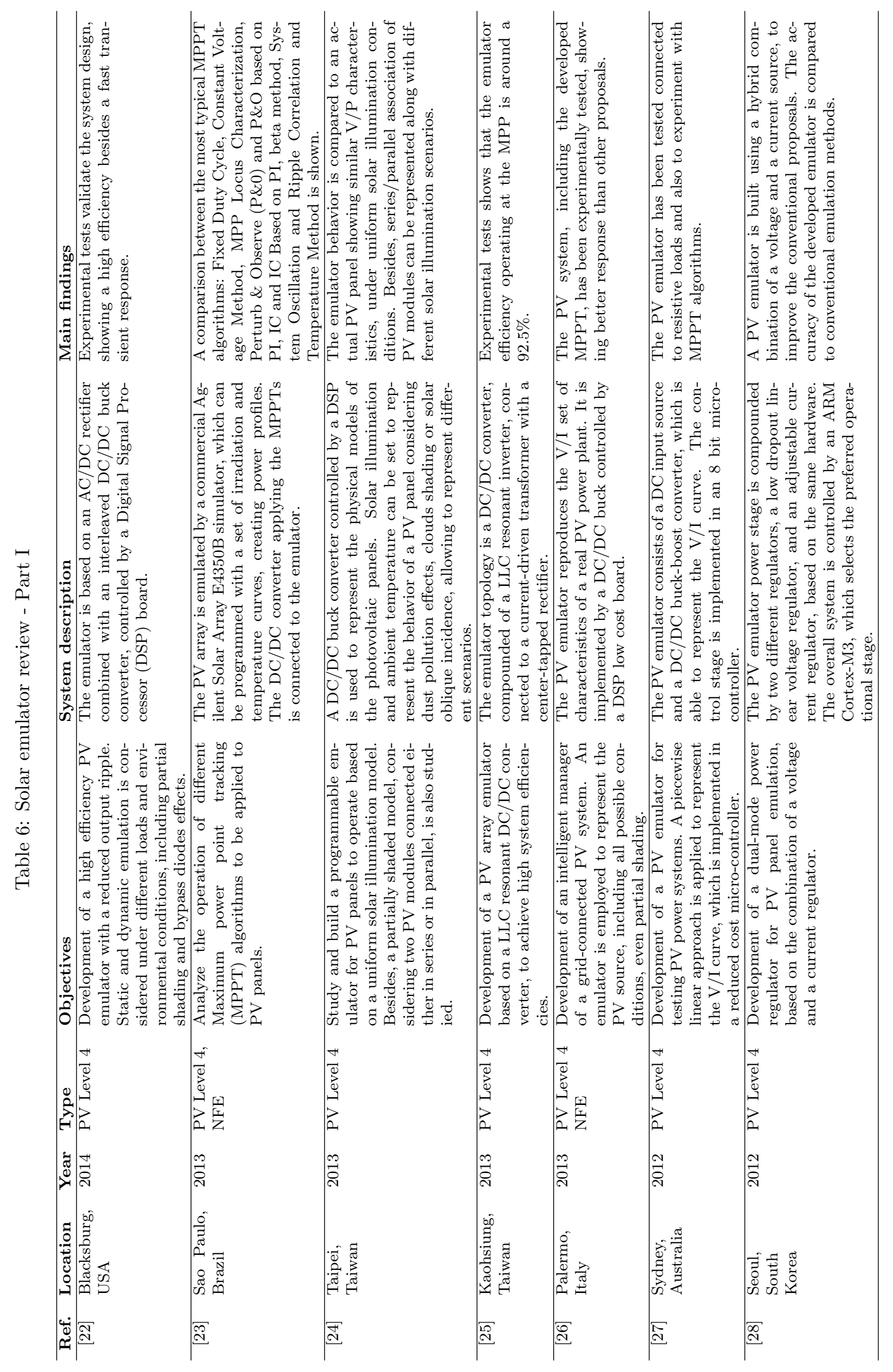




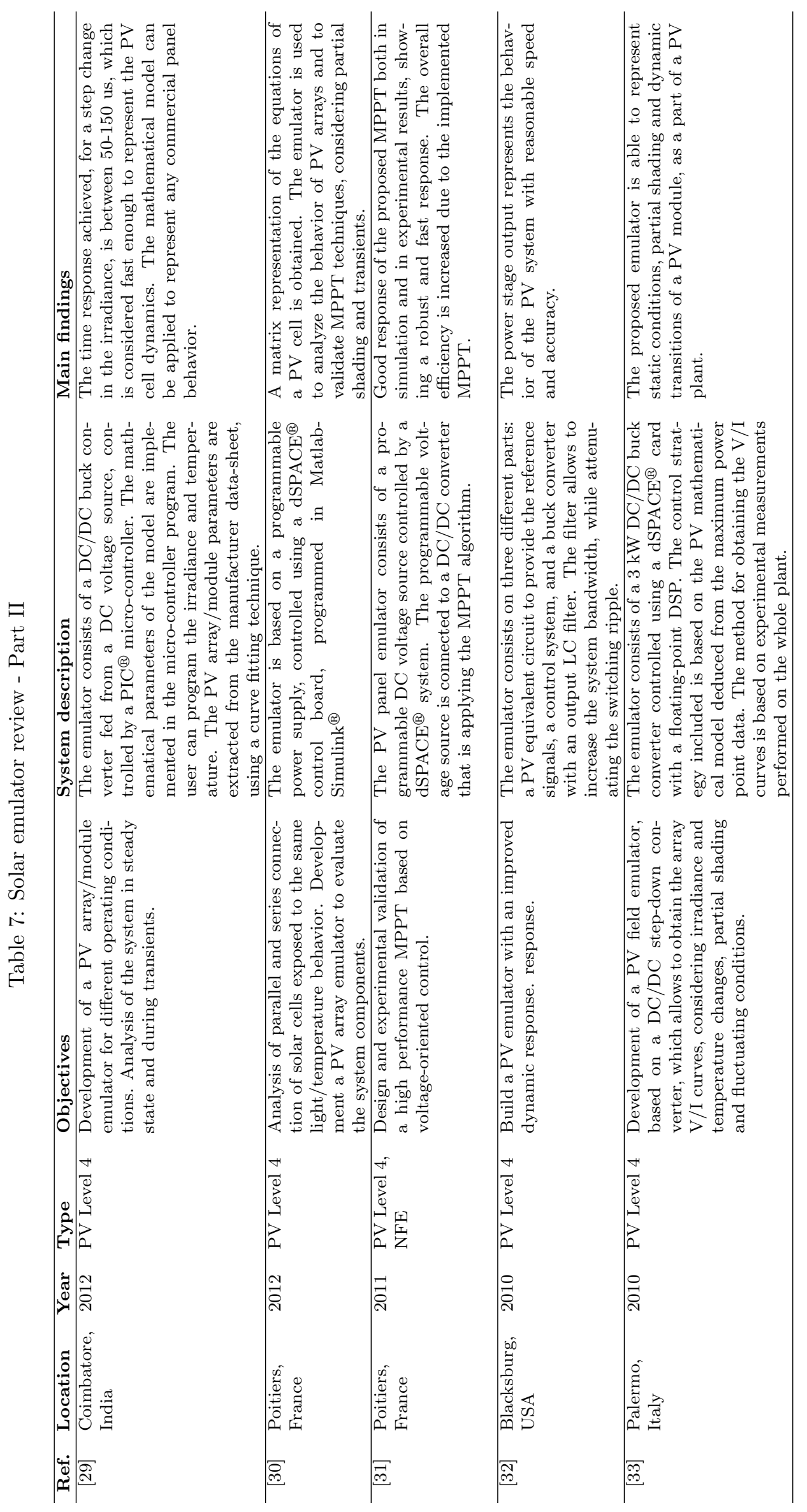




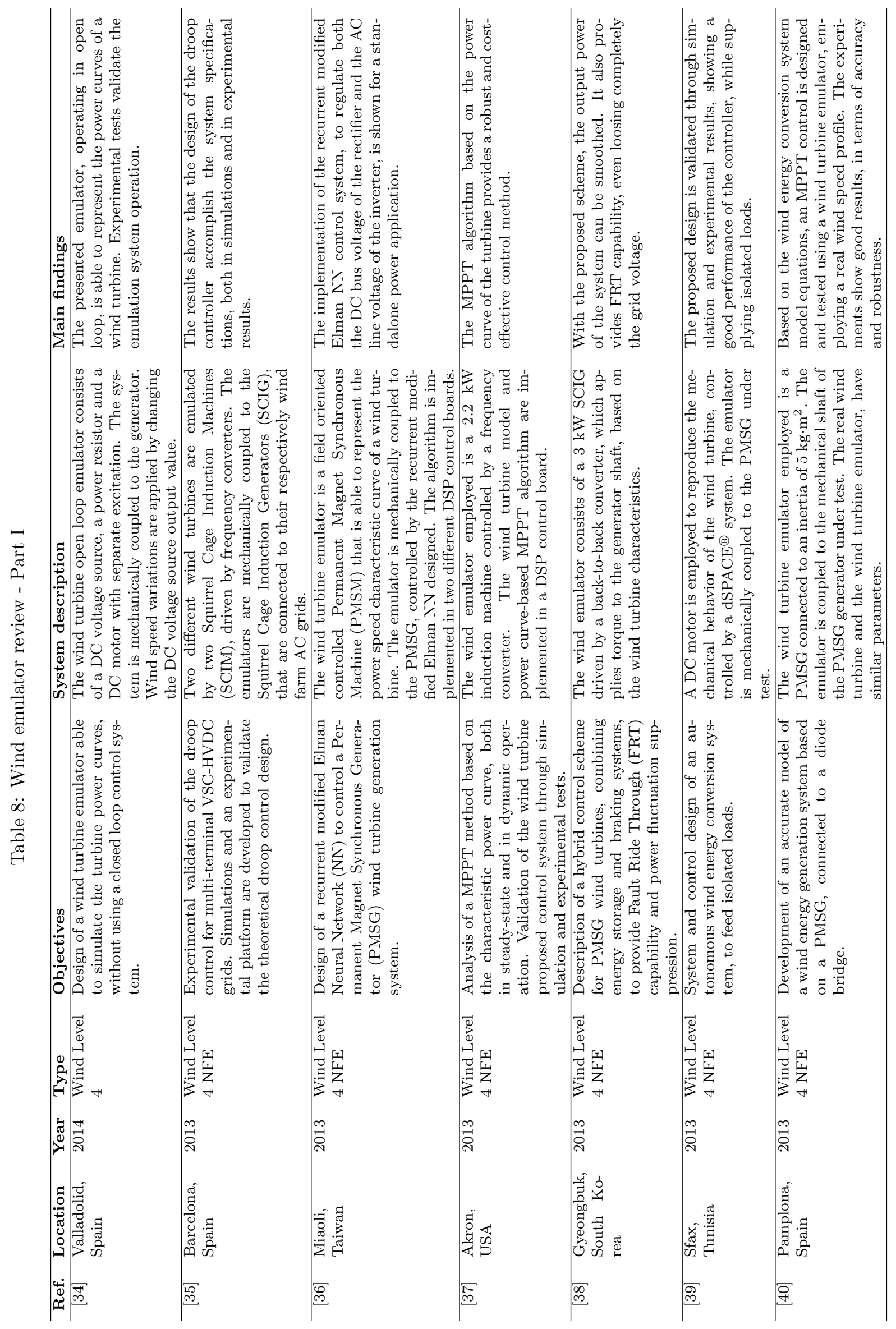




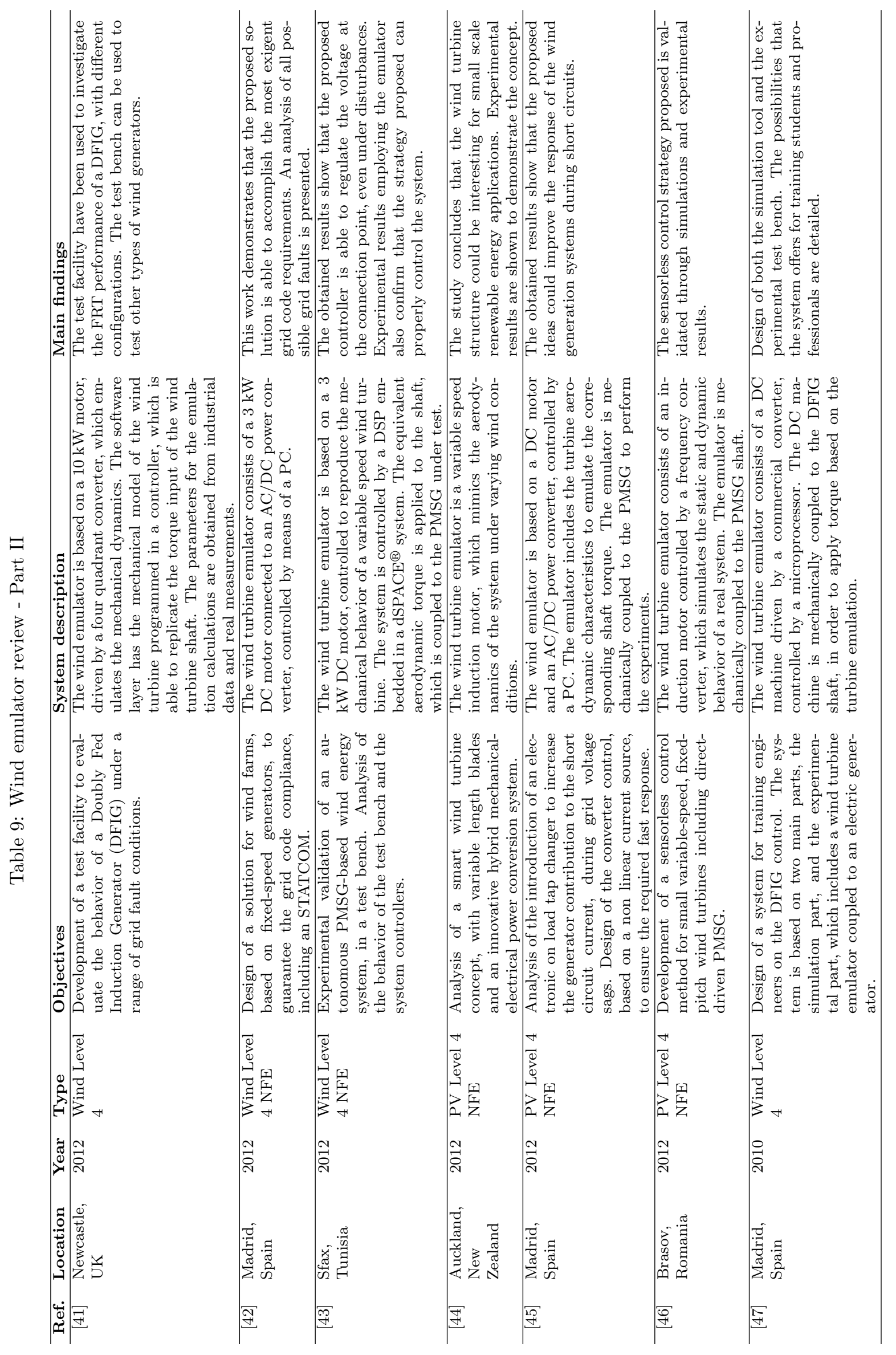




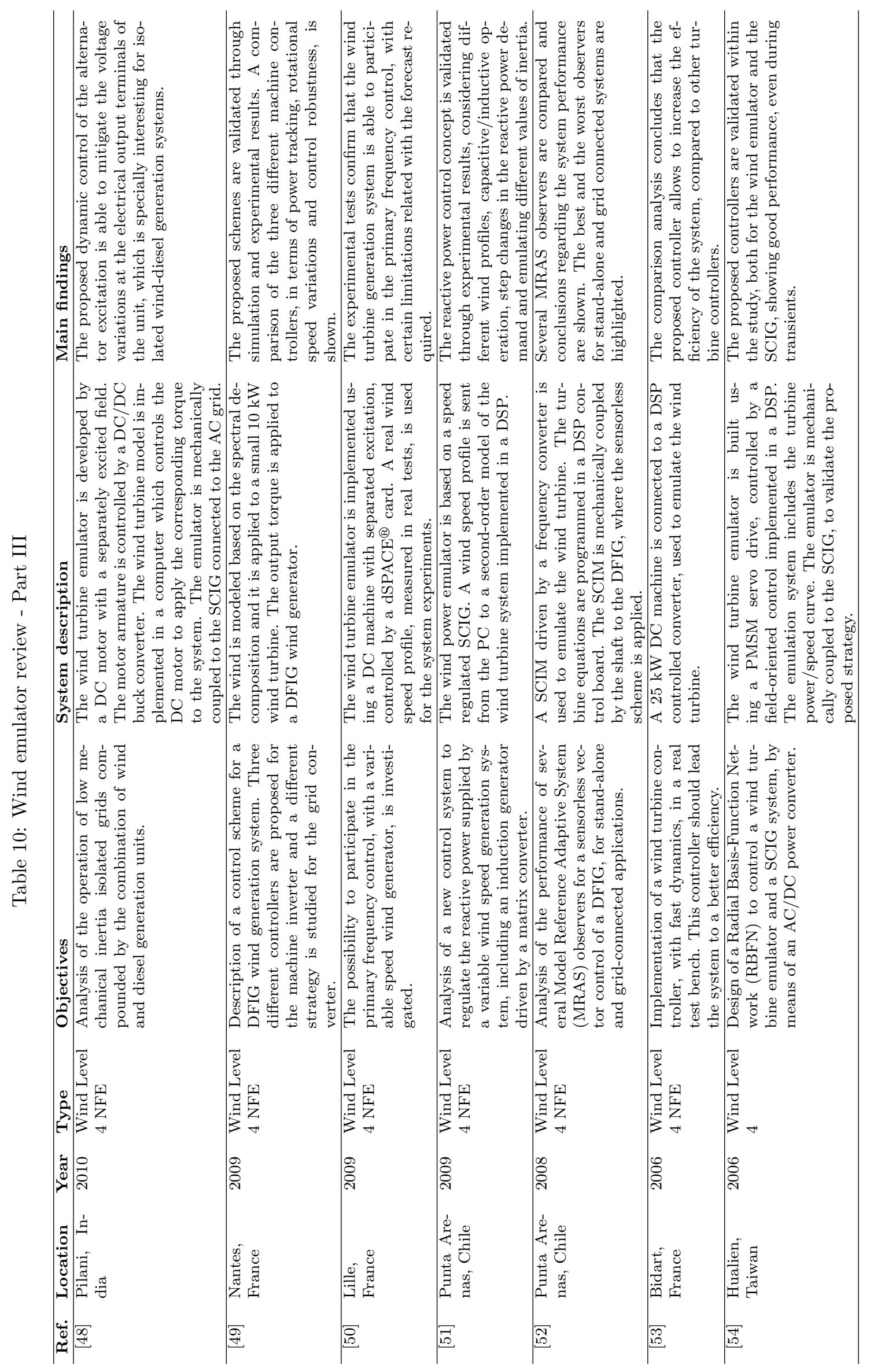




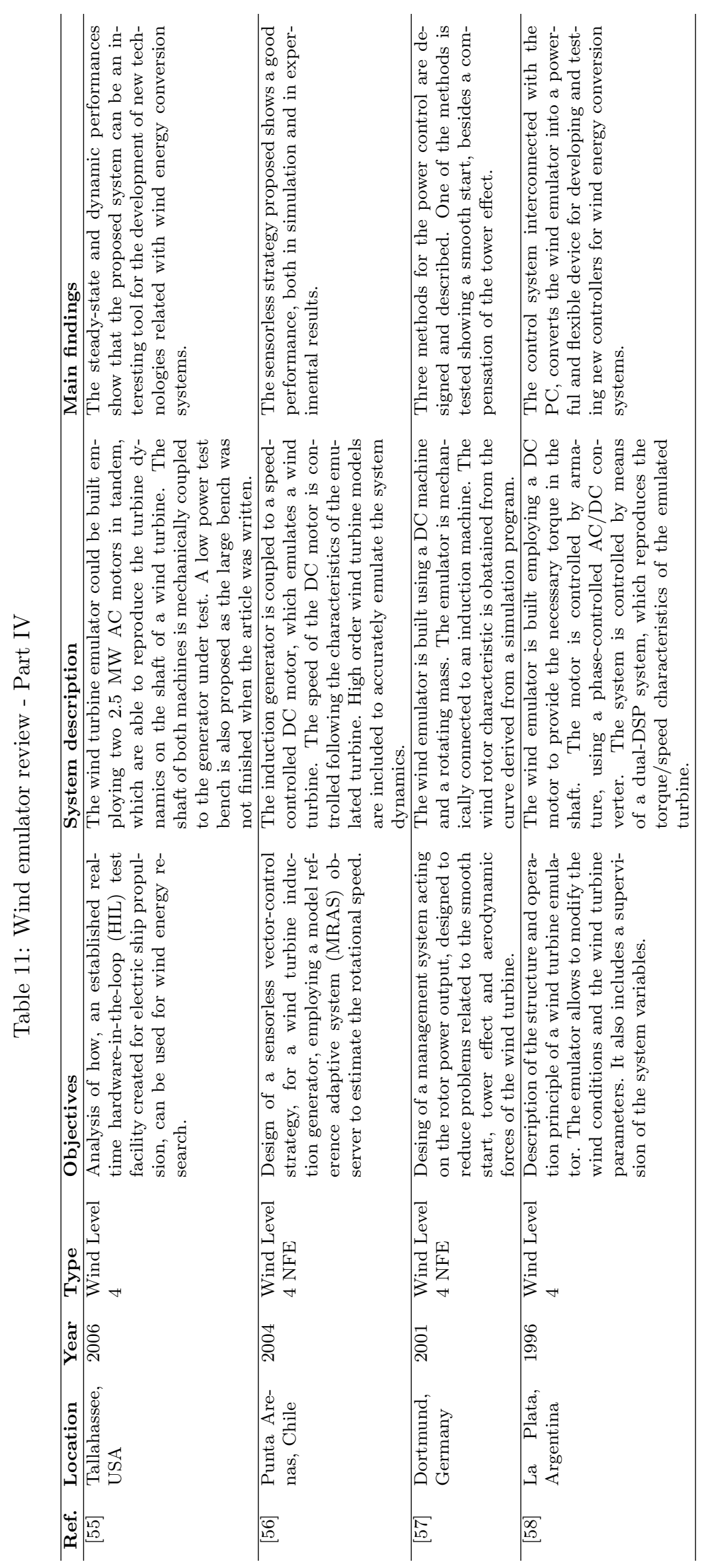




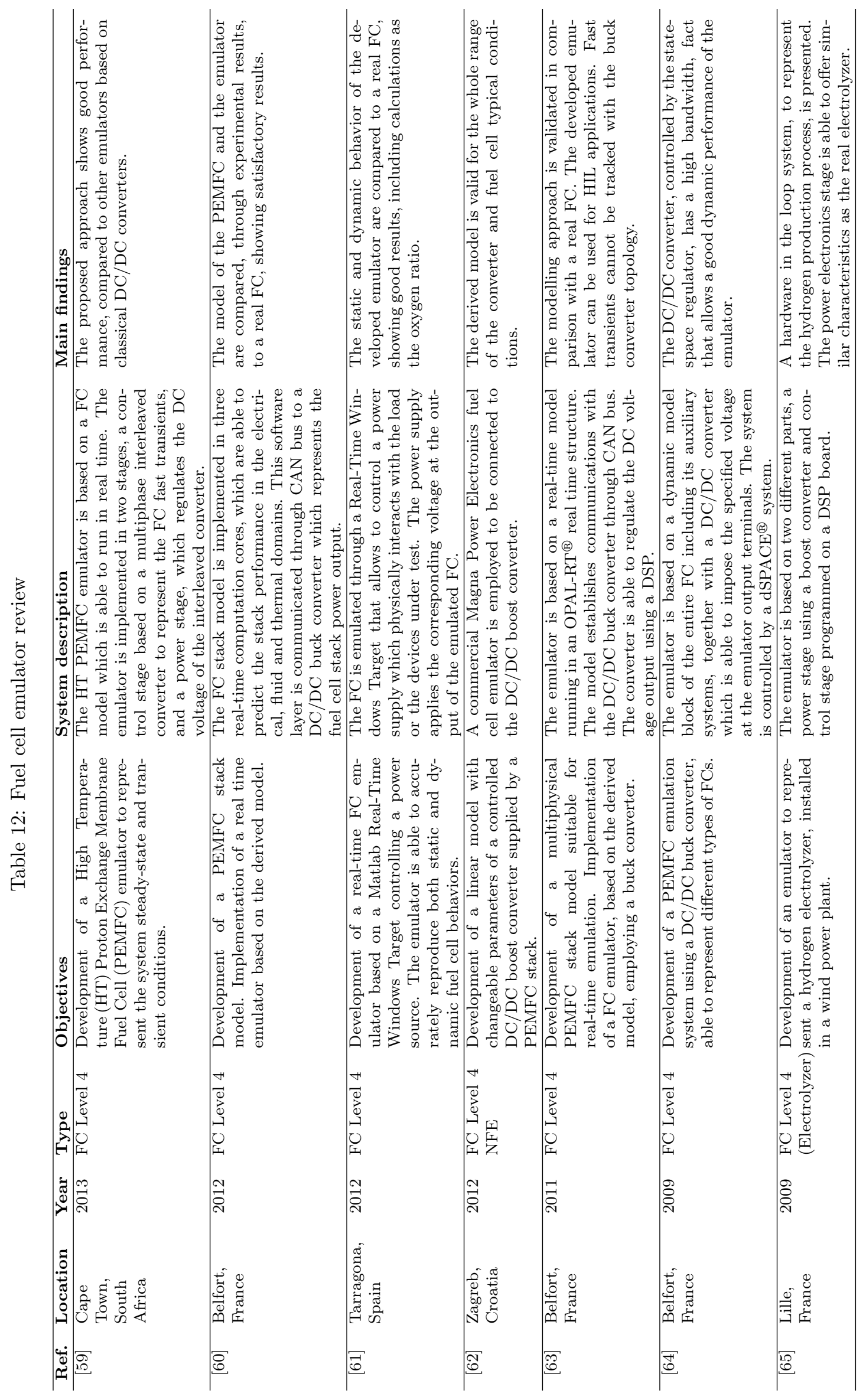




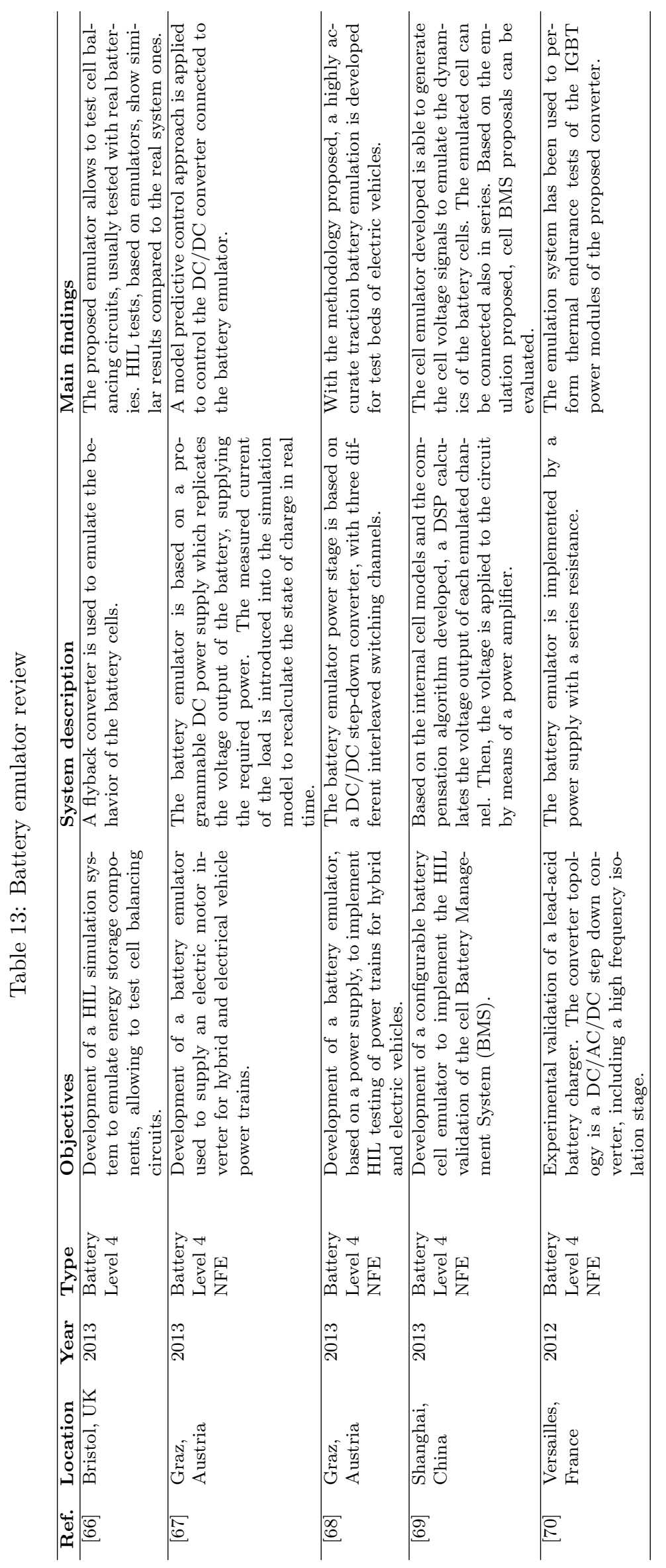




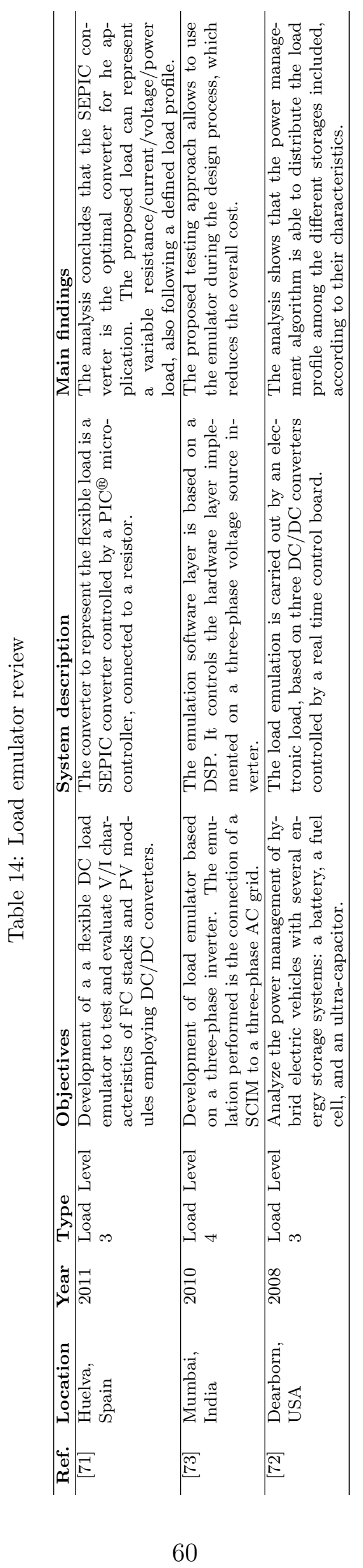




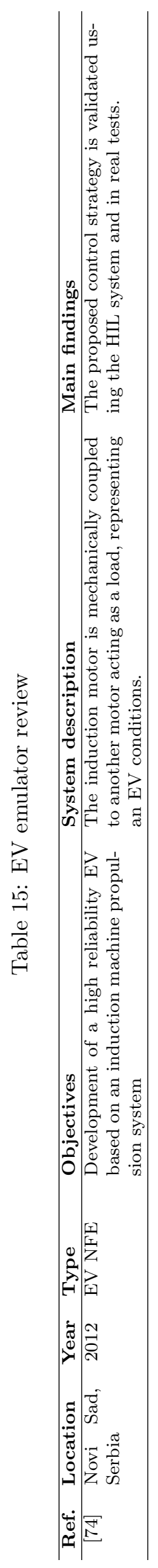

